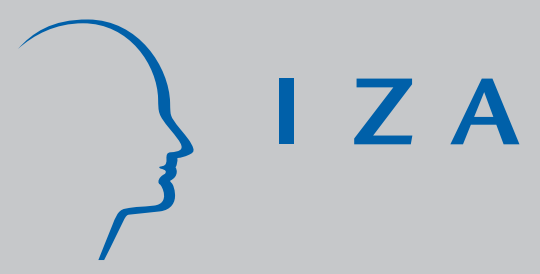

IZA DP No. 3126

The Catalysing Role of In-House R\&D in Fostering the Complementarity of Innovative Inputs

Alessandra Catozzella

Marco Vivarelli

October 2007 


\title{
The Catalysing Role of In-House R\&D in Fostering the Complementarity of Innovative Inputs
}

\author{
Alessandra Catozzella \\ University of Pavia \\ Marco Vivarelli \\ IPTS Seville, Catholic University of Milan, \\ CSGR Warwick and IZA
}

\section{Discussion Paper No. 3126 \\ October 2007}

\author{
IZA \\ P.O. Box 7240 \\ 53072 Bonn \\ Germany \\ Phone: +49-228-3894-0 \\ Fax: +49-228-3894-180 \\ E-mail: iza@iza.org
}

\begin{abstract}
Any opinions expressed here are those of the author(s) and not those of the institute. Research disseminated by IZA may include views on policy, but the institute itself takes no institutional policy positions.
\end{abstract}

The Institute for the Study of Labor (IZA) in Bonn is a local and virtual international research center and a place of communication between science, politics and business. IZA is an independent nonprofit company supported by Deutsche Post World Net. The center is associated with the University of Bonn and offers a stimulating research environment through its research networks, research support, and visitors and doctoral programs. IZA engages in (i) original and internationally competitive research in all fields of labor economics, (ii) development of policy concepts, and (iii) dissemination of research results and concepts to the interested public.

IZA Discussion Papers often represent preliminary work and are circulated to encourage discussion. Citation of such a paper should account for its provisional character. A revised version may be available directly from the author. 


\section{ABSTRACT \\ The Catalysing Role of In-House R\&D in Fostering the Complementarity of Innovative Inputs}

The aim of this study is to test the possible catalysing role of in-house R\&D in fostering the complementarity of innovative inputs on a sample of 3045 manufacturing firms drawn from the third Italian Community Innovation Survey (1998-2000). The interactions between four different sources of innovation - internal and external R\&D, embodied and disembodied technological acquisitions - have been simultaneously explored through the two (direct and indirect) testing frameworks for complementarity. Results from both the approaches show that the innovative process is a phenomenon combining within itself both complementarity and substitutability relationships, depending both on the typology of the targeted innovation output and on the particular combination of innovative inputs we focus on. In particular, it is in-house R\&D that seems to create the precondition allowing firms to enjoy complementarity effects. Indeed, the possibility of exploiting synergies between different innovative inputs turns out to be subordinated to having undertaken a minimum amount of internal R\&D. The implication of this result is that a role for in-house R\&D emerges, beyond its direct effect in generating an innovative output: even if internal research is not a necessary precondition for a firm to be innovative, it should still be carried out because of its important role in the generation of synergies that amplify the impacts of the other innovative inputs it interacts with.

JEL Classification: $\quad 031$

Keywords: $\quad$ R\&D, innovation, complementarity, supermodularity, substitutability

Corresponding author:

Marco Vivarelli

Facoltà di Economia

Università Cattolica

Via Emilia Parmense 84

I-29100 Piacenza

Italy

E-mail: marco.vivarelli@unicatt.it

\footnotetext{
* The authors would like to thank the ADELE Laboratory at ISTAT in Rome for the provision of CIS 3 data. Previous versions of this paper have been presented in seminars at the University of Pavia, the University of Lisbon, the university "Politecnico di Milano", and at the first European Conference on Corporate R\&D (CONCORD): "Knowledge for Growth: Role and Dynamics of Corporate R\&D", held at the Institute for Prospective Technological Studies (IPTS) in Sevilla, October 8-9, 2007. We wish to thank discussants and participants for their useful comments and suggestions. Precious insights by Mariacristina Piva are also gratefully acknowledged.
} 


\section{Introduction: is there something more than R\&D in innovation?}

Both theoretical and empirical works often use research activities and innovation as interchangeable concepts, sometimes using the justification of data availability and computational difficulties. Nevertheless - despite the claimed identification between the two concepts - it is easy to verify the difference between statistics representing the percentages of innovating firms and those computing the shares of R\&D performers out of the total. Mohnen and Röller (2005) use the first Community Innovation Surveys (CIS) from four countries (Ireland, Denmark, Germany and Italy) to show that, on average, only $55.2 \%$ of innovative firms declares to have invested in $R \& D$ activities. Almost the same percentage (55.3\%) emerges from the third Austrian CIS (García and Mohnen, 2004). By the same token, almost $40 \%$ of French innovative firms answering the third CIS declared they had not invested at all in R\&D (Mairesse and Mohnen, 2004), a percentage rising to $54.8 \%$ for the corresponding Italian data (ISTAT, 2004).

The explanation of these discrepancies should be looked for in the large exploitation of nonR\&D inputs; in fact, innovation emerges as a result of many diversified activities, including R\&D but also several other practices such as investment in plant, machinery and equipment ${ }^{1}$; engineering developments and experimentation; external technological acquisition, licensing agreements and so on. We should never forget that "Technological change undoubtedly enters the economy through many doors" (Rosenberg, 1976, pp. 65-66).

We need then to get over the scientification of innovation - the notion that R\&D activities always underpin the innovative output (Griliches, 1979) - to come to a more complete representation of technological change ${ }^{2}$. In re-evaluating the role of alternative sources of innovation, we will focus on the possibility that such innovative inputs are bound together by interdependencies (possibly complementarities) which may affect the firms' ultimate innovative performance. In particular, together with the simultaneous analysis of four different categories of innovative inputs, the main novelty of this study will be to test empirically the catalysing role of inhouse $R \& D$ in fostering innovative input complementarity on a sample of 3045 manufacturing firms drawn from the third Italian CIS (1998-2000). Thus, the main hypothesis of this study is that

\footnotetext{
${ }^{1}$ This is so-called "embodied technological change" whose role - already emphasized by Solow (1960) and Salter (1960) - is often neglected, in spite of firm-level and aggregate empirical studies confirming its quantitative relevance in explaining both innovation (see Parisi et al., 2006) and more general productivity growth (Hobijn, 1999).

${ }^{2}$ A related stream of literature, instead of looking at the possible complementarities between R\&D and other innovative inputs and at their ultimate effects in terms of firm's performance, is devoted to the determinants of the R\&D investment. While one of the authors has investigated this issue in other works (see Piva and Vivarelli, 2006 and 2007), this ex-ante perspective is out of the scope of the present contribution.
} 
internal research (IR) - albeit not being the sole innovative input - maintains a crucial pivotal role in determining a firm's innovative output.

The remainder of the paper is structured as follows: a theoretical, methodological and empirical discussion of complementarity is put forward in the following section; Section 3 is devoted to data; Section 4 presents the results from the indirect testing approach to complementarity; Section 5 carries out the statistical and econometric tests from the direct approach, while Section 6 briefly concludes.

\section{Complementarity in innovation activities}

The relationship linking innovation inputs to innovation outputs was labelled by Pakes and Griliches (1984) as “the knowledge production function”, mainly thought of as a relationship between R\&D and patents (see also, among others, Crèpon, Duguet and Mairesse, 1998, and Lööf and Heshmati, 2003). Nowadays, the availability of CIS surveys allows for more informative measures (product innovations, process innovations, share of innovative turnover) of innovative output to be used instead of the standard, highly questionable, patent counts. Quite surprisingly, despite the fact that the same surveys also provide us with measures of a variety of innovative inputs, the main focus of previous studies has remained - with few exceptions - R\&D alone.

It is probably because of such a restrictive input choice, that Mairesse and Mohnen (2004) conclude that "the greatest part of the innovation remains to be explained" (p. 11), a disappointing result which they show to be robust to the alternative measures of innovation output they adopt (either patents or the more specific CIS indicators). The obvious question is, then, where does such unexplained output come from?

Answering this question unavoidably calls for the introduction of additional-to-R\&D innovative inputs in the knowledge production function equation. However, this solution (which has been adopted recently, for example, by Parisi et al., 2006, and Conte and Vivarelli, 2005) paves the way to the question of what is the nature of the interactions taking place between different innovative inputs. This paper is devoted to shedding some light on this basic research question.

\subsection{Previous literature: the substitutability versus the complementarity hypothesis}

Two alternative views can be adopted in order to describe the nature of relationships between innovative inputs: the substitutability view and the complementarity view. The substitutability approach looks at the different identified innovative inputs as stand-alone activities mainly acting as substitute sources of innovation: such a view clearly focuses on individual 
practices, their pros and cons and the choice between them. In this sense, one may refer to firms' investment decisions as a "Make or Buy" problem: embodied technological change and disembodied technological acquisition (consisting in purchasing technology from outside) are both perceived as alternatives to in-house R\&D. However, the empirical evidence supporting the substitutability approach is often based on specific sectors and/or partial definitions of external technological sources. For instance, Pisano (1990) found that US biotechnological firms with high levels of accumulated internal knowledge (high $R \& D$ ) invested almost exclusively in in-house research activities. Some evidence of substitutability is also found by Basant and Fikkert (1996) and Fernandez-Bagües (2004): however, while the former analyse the interaction between internal R\&D and licensing agreements only, the latter just focus on the relationship between internal and external pharmaceutical $R \& D$ projects.

The alternative view - complementarity - claims for the existence, within the innovation process, of synergic effects making the simultaneous adoption of different inputs more valuable than the separate investment in each of them. Some measure of innovative performance, adequately checked for firm and industry fixed effects, has to be computed in order to test complementarity vs substitutability.

For example, Cassiman and Veugelers (2006) use the percentage of sales generated from new or substantially improved products in order to test the complementarity hypothesis on a crosssection of 269 Belgian manufacturing firms answering the first CIS (1993). The authors focus on two inputs only: internal R\&D and disembodied technological acquisitions ${ }^{3}$; once checked for firm and industry characteristics, they find strong empirical evidence in support of complementarity. This result is consistent with previous research by Veugelers (1997) showing that external knowledge sources stimulate internal research activities, at least for firms with internal R\&D departments: externally acquired knowledge seems to leverage the innovative productivity of inhouse R\&D (see also Lokshin, Belderbos and Carree, 2006)

Symmetrically, investing in internal R\&D activities should help the firm in scanning the environment for existing available technologies and evaluating them; this could explain, for example, the findings of Lokshin et al. (2006). Using a balanced panel data of 304 Dutch manufacturing firms covering the years 1996-2001 they show that a positive effect of external R\&D on labour productivity only emerges when internal research activities are also performed. This evidence in favour of the complementarity hypothesis is consistent with what Cohen and Levinthal

\footnotetext{
${ }^{3}$ The latter category includes four activities: licensing agreements, external R\&D, acquisition of other
} companies ("take-over") and recruitment of skilled workers. 
(1989) defined "absorptive capacity" externally performed innovation (see also: Griffith et al., 2003).

\subsection{A theoretical discussion of complementarity}

The standard analytical implementation of the complementarity hypothesis rests upon a cardinal view of the concept: a twice-differentiable payoff function (in our case the innovative output) $\Pi(\mathrm{y}, \mathrm{z})$ is introduced as a function of a $(1 \mathrm{x} \mathrm{n})$ vector $\mathrm{y}$ of endogenously determined practices (in our case the innovative inputs) and a (1 x k) vector $\mathrm{z}$ of exogenous factors. The (necessary and sufficient) condition for the practices $y_{i}$ and $y_{j}$ to be complementary is to find nonnegative mixed-partial derivatives:

$$
\frac{\partial^{2} \Pi(y, z)}{\partial y_{i} \cdot \partial y_{j}} \geq 0 \forall \mathrm{z}
$$

This is equivalent to saying that the marginal returns on one activity increase in the level of the other, for any given value of the other arguments of П. Such a definition, however, fits only a subset of the economic problems we deal with. Indeed, two restrictive requirements have to be satisfied in order for condition (1) to be checked out:

1. differentiability of the objective function;

2. divisibility of the choice variables ${ }^{5}$.

Indeed, when analysing the innovative process, we often have to deal with issues like increasing returns and indivisibilities: the latter is surely the case of $R \& D$ expenditures, entailing a minimum starting investment, sunk costs and some degree of persistence over time (Beneito, 2003). Moreover, complementarity itself might be the main (endogenous) source of non-convexities insofar as it requires the co-ordination of several activities: given two complementary practices $\mathrm{y}_{\mathrm{i}}$ and $y_{j}$, the firm might have no incentive in increasing any of them individually, but still find an advantage in increasing both of them simultaneously.

Even more strongly, it may well happen that a practice can be implemented if and only if some other activity is already carried out at a minimum threshold level ${ }^{6}$. This is clearly in contrast

\footnotetext{
4 "firm's ability to identify, assimilate, and exploit knowledge from the environment" (Cohen and Levinthal, 1989, p. 570).

${ }^{5}$ The possible discrete nature or partial indivisibility of one or more practices gives rise to a non-convex decision problem that cannot be interpreted with the traditional instruments of mixed partial derivatives.

${ }^{6}$ This seems to be the case of "buy" innovative strategies, often available (or exploitable) only on an exchange basis: that is why, for example, analysing the relationship between internal and external R\&D in fact comes down to exploring the choice between a pure "make" strategy and a mixed "make \& buy" one. Using a representative sample of Italian manufacturing firms, Piga and Vivarelli (2003 and 2004) show that, once firms decide to engage in any (internal and/or external) R\&D activity, only a minority of them (8.6\%)
} 
with the standard idea of a smooth concave production function and requires the adoption of a sublattice structure (see Topkis (1998) for a definition) ${ }^{7}$. Such a change of perspective implies a more general way of thinking of complementarity: the ordinal view suggested by Edgeworth: "activities are Edgeworth complements if doing (more of) any one of them increases the returns to doing (more of) the others”. (Milgrom and Roberts, 1995, p. 181). This definition, which incorporates the standard differentiable framework as a special case without imposing the same restrictive conditions, finds its natural formalisation in the mathematical theory of supermodularity: taking again an objective function $\Pi(\mathrm{y}, \mathrm{z}): \mathrm{R}^{\mathrm{n}+\mathrm{k}} \rightarrow \mathrm{R}$, we say that it is supermodular in $\mathrm{y}$ if, for all $\mathrm{y}$ and $\mathrm{y}^{\prime} \in \mathrm{R}^{\mathrm{n}}$, and for all $\mathrm{z} \in \mathrm{R}^{\mathrm{k}}$ :

$$
\Pi\left(y \vee y^{\prime}\right)-\Pi\left(y^{\prime}\right) \geq \Pi(y)-\Pi\left(y \wedge y^{\prime}\right)
$$

where $y \vee y^{\prime}$ denotes the component-wise maximum and $y \wedge y^{\prime}$ the component-wise minimum of $\mathbf{y}$ and $\mathbf{y}^{\prime 8}$. The previous expression is equivalent to:

$$
\Pi\left(y \vee y^{\prime}\right)+\Pi\left(y \wedge y^{\prime}\right) \geq \Pi(y)+\Pi\left(y^{\prime}\right)
$$

which means that increasing all the practices simultaneously is better than increasing each of them separately. Increasing any activity, in the context of a supermodular function, is more effective when the others are already high; this is precisely the definition of complementarity. In the particular case of a twice continuously differentiable payoff function $\Pi$, supermodularity is equivalent to the condition of non-negative mixed partial derivatives (1).

It should be remarked, however, that neither the cardinal nor the ordinal definitions of complementarity require this property to be a global one: we might think, instead, of a local validity of (pair-wise) complementarity in the context of multiple interactions; in particular, it may be that complementarity between practices $\mathrm{y}_{1}$ and $\mathrm{y}_{2}$ only emerges once a certain threshold has been achieved either by one of the two practices or by a third practice $\mathrm{y}_{3}$ they interact with.

choose a pure "buy" strategy completely excluding the use of internal facilities. Even more extreme is the case of cooperative innovative activities, usually requiring a direct commitment on behalf of each involved firm as an almost necessary precondition to cooperation. For instance, Cassiman and Veugelers (2002), using data from the first Belgian CIS, found no firms cooperating while not performing any in-house R\&D.

${ }^{7}$ It suffices here to observe that, given $y$ and $y^{\prime}$ such that $y^{\prime} \geq y$, then the joint set $\left\{y^{\prime}, y\right\}$ is a sublattice. It follows that, requiring the vector of practices $y$ to belong to such a sublattice, we are in fact imposing the constraint that the only feasible alternative to $\mathrm{y}$ is the vector $\mathrm{y}^{\prime}$ obtained by increasing all the inputs simultaneously.

${ }^{8}$ The component-wise maximum (minimum) of $\mathrm{y}$ and $\mathrm{y}^{\prime}$ ( $\mathrm{y}$ and $\mathrm{y}^{\prime} \in \mathrm{R}^{\mathrm{n}}$ ) being the ( $\left.\mathrm{n} \mathrm{x} 1\right)$ vector whose $i^{\text {th }}$ component is: $\max \left(y_{i}, y_{i}^{\prime}\right)\left(\min \left(y_{i}, y_{i}^{\prime}\right)\right)$. 


\subsection{Empirical tests of complementarity and substitutability: a methodological framework.}

\subsubsection{The direct approach}

The "direct approach" is based on the intuition lying behind the idea of complementarity: the simultaneous adoption of different inputs should prove to be more valuable than adopting each of them separately. To prove complementarity then it should be sufficient to compare the contribution of alternative strategies (i.e. alternative combinations of practices) in generating value for the firm.

Turning to the topic we are interested in, this translates into focusing directly on the link between innovative inputs (and their bundling) and innovative performance. Once the best (available) performance measure has been chosen, the direct approach simply consists in evaluating how it is affected by interactions between alternative inputs, an evaluation which has to be differently performed according to the differentiable or non-differentiable nature of the analysed inputs.

In a standard differentiable framework - characterised by continuous measures of innovative inputs - the (necessary and sufficient) condition is (1). In order for this condition to be verified, the performance measure $\Pi$ has to be regressed on the entire set of potentially important practices y and their pair-wise interactions ${ }^{9}$ (besides checking, of course, for the set $\mathrm{Z}$ of exogenous factors - such as sectoral and firm's specificities - that are likely to affect the adopted measure of performance):

$$
\Pi^{t}=\left(y^{t}\right)^{\prime} \cdot \alpha+\sum_{i \neq j} \beta_{i j} \cdot y_{i}^{t} \cdot y_{j}^{t}+\left(z^{t}\right)^{\prime} \cdot \gamma+\varepsilon^{t}
$$

where $t$ denotes the firm index, coefficients of the vector $\alpha$ indicate the partial contribution of each single input to the performance $\Pi$; positive and significant coefficients on interactions between any two innovative expenditures $\left(\beta_{\mathrm{ij}} \geq 0, \mathrm{i} \neq \mathrm{j}\right)$ have to be interpreted as indicators of complementarities $^{10}$. Then inspecting complementarity will come down to carrying out simple onetailed t-tests on the $\frac{n !}{2 ! \cdot(n-2) !}$ interaction coefficients.

This procedure, which is correct when $n=2$, turns out to be incomplete when applied to problems characterised by more-than-two practices in that it neglects the existence of complementarity relationships between groups - not just pairs - of activities ${ }^{11}$ as well as the

\footnotetext{
${ }^{9}$ Resorting to the combinatorial notation, $\frac{n !}{2 ! \cdot(n-2) !}$ terms will have to be included, expressing all the simple combinations of our $\mathrm{n}$ activities, taken two at a time $\left(\mathrm{C}_{\mathrm{nk}}\right.$ with $\left.\mathrm{k}=2\right)$.

${ }^{10} \beta_{\mathrm{ij}}>0$ in order for strict complementarity to hold, thus excluding the possibility that the adoption of one input produces no impact on the returns associated with the adoption of the other.

${ }^{11}$ This is the case, among others, for Athey and Stern (2002) and Bresnahan et al. (2002).
} 
possibility that such pair-wise relationships change in nature over the domain of other endogenously-chosen practices (threshold effects).

Both these issues are crucial in the context of the innovative process whose generation, involving a large variety of inputs potentially interacting with each other, clearly calls for a broader empirical test of complementarity. First, we need to rearrange the standard definition of complementarity presented in equations 2 and 3 in such a way as to allow for group (instead of just pair-wise) input interactions. Second, multiple inequality restrictions should be tested. An interesting approach to these problems has been suggested by Lokshin, Belderbos and Carree $(2004)^{12}$ on the basis of the multiple-inequality-restrictions testing framework developed by Kudô (1963) and Wolak (1989): the central departure from the standard direct approach consists in entering multiple (in addition to pair-wise) interaction terms to the performance equation, as shown in equation (5):

$$
\begin{aligned}
& \Pi^{t}=\left(y^{t}\right)^{\prime} \cdot \alpha+\sum_{i \neq j} \beta_{i j} \cdot y_{i}^{t} \cdot y_{j}^{t}+\sum_{i \neq j \neq k} \beta_{i j k} \cdot y_{i}^{t} \cdot y_{j}^{t} \cdot y_{k}^{t}+ \\
& +\ldots+\beta_{12 \ldots n} \cdot \prod_{i=1}^{n} y_{i}+\left(z^{t}\right)^{\prime} \cdot \gamma+\varepsilon^{t}
\end{aligned}
$$

or, in a more compact notation:

$$
\Pi^{t}=\left(y^{t}\right)^{\prime} \cdot \alpha+\sum_{\theta=2}^{n} \sum_{s \theta=1}^{\frac{n !}{\theta ! \cdot(n-\theta) !}} \beta_{s \theta} \cdot \prod^{s \theta} y_{i}+\left(z^{t}\right)^{\prime} \cdot \gamma+\varepsilon^{t}
$$

$\theta$ being the number of inputs each interaction involves (from $2=$ pair-wise interactions, to $n=$ multiple interaction between all the adopted activities), while $s \theta$ identifies the specific interaction we are referring to (the total number of interactions being, for any given $\theta, C_{n \theta}=\frac{n !}{\theta ! \cdot(n-\theta) !}$ ).

It is easy to check that the mixed partial derivatives we are interested in are no longer constant once multiple interaction terms have been introduced: their value (and, consequently, their sign) will depend now on the value taken by all the other practices they interact with:

$$
\frac{\partial \prod^{t}}{\partial y_{i} \partial y_{j}}=\beta_{i j}+\sum_{k \neq i \neq j} \beta_{i j k} \cdot y_{k}^{t}+\ldots+\beta_{12 \ldots n} \cdot \prod_{k \neq i \neq j} y_{k}
$$

12 The authors exhaustively present the cases of 2, 3 and 4 practices, suggesting the importance of introducing multiple practice interactions in the field of innovation. 
Now, in order for complementarity (substitutability) to be verified, these mixed partial derivatives should be non-negative (non-positive) for all possible values of the other practices ( $\mathrm{y}_{\mathrm{k}}$; with $\mathrm{k} \neq \mathrm{i}$ and $\neq \mathrm{j}$ ), and strictly positive (negative) in at least one case. Thus, computationally unfeasible multiple integrals would be drawn in.

Lokshin, Belderbos and Carree (2004) suggest a feasible solution to this problem, drawing on the intuition that if inequalities hold for all possible combinations of the largest and the lowest values taken on by each practice, then they will hold for all the other value combinations. In other words, we can restrict each practice $y_{k}$ to taking on just two values $\left(\min \left(y_{k}\right)\right.$ and $\left.\max \left(y_{k}\right)\right)$, as if they were dichotomous variables: then, the number of constraints to be simultaneously tested for each pair of practices will be $2^{n-2}$, for a total of $C_{n 2} \cdot 2^{n-2}=\frac{n !}{2 ! \cdot(n-2) !} \cdot 2^{n-2}$ inequality constraints.

In this paper we will discuss four innovation practices: $y_{i}(i=1,2,3,4)$. Thus, we will deal with $C_{42} \cdot 2^{2}=\frac{4 !}{2 ! \cdot 2 !} \cdot 2^{2}=24$ inequality constraints to be tested, 4 for each pair of inputs $\left(\mathrm{y}_{\mathrm{i}}\right.$ and $\left.\mathrm{y}_{\mathrm{j}}\right)$ :

$$
\left\{\begin{array}{l}
\beta_{i j}+\beta_{i j k} \cdot \min \left(y_{k}\right)+\beta_{i j l} \cdot \min \left(y_{l}\right)+\beta_{i j k l} \cdot \min \left(y_{k}\right) \cdot \min \left(y_{l}\right) \geq 0 \\
\beta_{i j}+\beta_{i j k} \cdot \min \left(y_{k}\right)+\beta_{i j l} \cdot \max \left(y_{l}\right)+\beta_{i j k l} \cdot \min \left(y_{k}\right) \cdot \max \left(y_{l}\right) \geq 0 \\
\beta_{i j}+\beta_{i j k} \cdot \max \left(y_{k}\right)+\beta_{i j l} \cdot \min \left(y_{l}\right)+\beta_{i j k l} \cdot \max \left(y_{k}\right) \cdot \min \left(y_{l}\right) \geq 0 \\
\beta_{i j}+\beta_{i j k} \cdot \max \left(y_{k}\right)+\beta_{i j l} \cdot \max \left(y_{l}\right)+\beta_{i j k l} \cdot \max \left(y_{k}\right) \cdot \max \left(y_{l}\right) \geq 0
\end{array}\right.
$$

Unfortunately, despite this simplification - and the possibility, demonstrated by Topkis (1998), to check complementarity separately for each pair of practices $y_{i}$ and $y_{j}$ in order that the payoff function $\Pi$ be supermodular over the full set $y$ - a number of methodological and computational difficulties still remain.

First of all, the simultaneous test of multiple inequality restrictions cannot be dealt with by resorting to the standard statistical distributions: indeed, the corresponding Wald (distance) statistics do not follow, under the null, a standard $\chi^{2}$ distribution but a mixture of $\chi^{2}$ whose weights call for multiple integrals to be (numerically) solved. Although Kodde and Palm (1986) have computed lower and upper bounds for this kind of test, a definite rejection (acceptance) of the null can not always be reached, the test being inconclusive whenever its statistic falls between the two bounds ${ }^{13}$.

\footnotetext{
${ }^{13}$ See Section 5.3 for further details.
} 
Moreover, given that the two hypotheses are non-nested ${ }^{14}$, the multiple-inequalities testing framework does not allow to test them one against the other; hence, two separate tests are called for.

Finally, whenever multiple inequality constraints have to be tested simultaneously, a probability exists that such inequalities turn out to assume opposite signs: more precisely, as long as the sign of the estimated inequalities depends on the values taken by all the other endogenous practices $\mathrm{y}_{\mathrm{k}}(\mathrm{k} \neq \mathrm{i} \neq \mathrm{j})$ ambiguous results might emerge supporting complementarity between $\mathrm{y}_{\mathrm{i}}$ and $\mathrm{y}_{\mathrm{j}}$ for certain combinations of other inputs' values, and substitutability for others. Such an outcome might involve the rejection of both the hypothesis of complementarity and that of substitutability, thus leading again to an inconclusive result.

However, there is the possibility that the nature of the relationship between inputs is local, changing over the domain of other (one or more) endogenously chosen variables. Once such a possibility is taken into account, the coexistence of opposite-sign inequality constraints might be interpreted as being itself a signal of complementarity endogeneity as well as an indicator of the sources of such endogeneity. In other words, inconclusive results must not necessarily be interpreted as indicating independence or indefinite relationships: they can instead be taken as first evidence in favour of complementarity endogeneity (that is, complementarity between $y_{i}$ and $y_{j}$ conditional on having performed another activity $\mathrm{y}_{\mathrm{k}}$ or even having performed it over a certain threshold). It becomes important then to discriminate between these two alternative interpretations: to our knowledge no specific testing procedure has been developed to this aim.

A possible way of filling this gap is that of re-shaping the above-presented testing procedure to render it more flexible, allowing the payoff function to switch from submodularity to supermodularity (or the reverse) as far as different firm's strategies are involved. More precisely, the standard procedure can be modified in order to verify whether any complementarity emerges between seemingly substitutable inputs once a minimum threshold level for one or more endogenous practices has been overcome, limiting the domain of the endogenous practices $\mathrm{y}_{\mathrm{k}}$ we suspect to be the source of systemic effects between $y_{i}$ and $y_{j}$. In particular, the overall lowest value of $\mathrm{y}_{\mathrm{k}}$ will be replaced by a minimum threshold level (for instance, a given $\mathrm{y}_{\mathrm{k}}$ 's percentile) leaving the maximum unchanged. The test will then work according to the same logic underlying the general procedure, that is checking the mixed partial derivatives' positiveness for all possible values of the other practices, except for the $y_{k}$ values artificially restricted to being higher than a minimum threshold. Resuming the previous example for $n=4$, the complementarity test (8) between $y_{i}$ and $y_{j}$ would now become:

\footnotetext{
${ }^{14}$ Indeed, while complementarity requires that the estimated inequalities be non-negative (strictly positive in at least one case), substitutability requires that the same inequalities be non-positive (strictly negative in at least one case), the two requirements thus being neither nested nor complementary.
} 


$$
\left\{\begin{array}{l}
\beta_{i j}+\beta_{i j k} \cdot p^{t h}\left(y_{k}\right)+\beta_{i j l} \cdot \min \left(y_{l}\right)+\beta_{i j k l} \cdot p^{t h}\left(y_{k}\right) \cdot \min \left(y_{l}\right) \geq 0 \\
\beta_{i j}+\beta_{i j k} \cdot p^{t h}\left(y_{k}\right)+\beta_{i j l} \cdot \max \left(y_{l}\right)+\beta_{i j k l} \cdot p^{t h}\left(y_{k}\right) \cdot \max \left(y_{l}\right) \geq 0 \\
\beta_{i j}+\beta_{i j k} \cdot \max \left(y_{k}\right)+\beta_{i j l} \cdot \min \left(y_{l}\right)+\beta_{i j k l} \cdot \max \left(y_{k}\right) \cdot \min \left(y_{l}\right) \geq 0 \\
\beta_{i j}+\beta_{i j k} \cdot \max \left(y_{k}\right)+\beta_{i j l} \cdot \max \left(y_{l}\right)+\beta_{i j k l} \cdot \max \left(y_{k}\right) \cdot \max \left(y_{l}\right) \geq 0
\end{array}\right.
$$

where $\mathrm{p}^{\text {th }}\left(\mathrm{y}_{\mathrm{k}}\right)$ stands for $\mathrm{y}_{\mathrm{k}}$ 's $\mathrm{p}^{\text {th }}$ percentile.

Testing for different $\mathrm{y}_{\mathrm{k}}$ and progressively higher threshold levels, the source of (local) input complementarity, if such a source does exist, should then emerge unequivocally.

While such a method, accounting for the possibility of local complementarity, is likely to attenuate the risk of inconclusive test results, it still suffers from the main drawback of the direct approach, possibly undermining its reliability, i.e. that the inclusion of all the practices and their interactions in eq. (5) might generate serious multicollinearity problems, making it impossible, in practice, to interpret the estimated coefficients and their significance. Obviously, omitting some of them is not a solution; given the possible correlation between practices, any empirical model separately estimating the impact of each input on innovative performance will be biased due to the omission of the other correlated variables.

The trade-off between the omitted-variable and the multicollinearity problem can be solved only by giving up some of the information we dispose of, in our case, the continuous measurement of innovative inputs in terms of expenditure levels. Thus, we have to think of each innovative input as a discrete-choice variable (just “yes or not” instead of "how much") and use them to create nonoverlapping categories identifying all the possible combinations of practices. Then, our performance measure (the innovative output) will be regressed on dummies exclusively identifying each system (plus the usual set $\mathrm{Z}$ of exogenous characteristics). Obviously, in implementing discrete instead of continuous regressors, we move from a standard convex decision set to a nonconvex one, requiring the tools of a non-differentiable framework.

Practically, this approach still requires the identification of an adequate performance measure ( $\Pi$ ), to be regressed on the standard set of controls $Z$, and a set of innovative input dummy variables $S_{1}$ identifying all the possible (mutually exclusive) combinations of our inputs. In our case, if $\mathrm{n}$ innovative inputs are considered (each taking value 1 if it has been adopted, 0 otherwise), $2^{\mathrm{n}}$ alternative systems of practices will be included in the performance equation:

$$
\Pi^{t}=\sum_{l=1}^{2^{n}} \delta_{l} \cdot S_{l}^{t}+\left(z^{t}\right)^{\prime} \cdot \gamma+\varepsilon^{t}
$$


Once eq. (10) has been estimated, complementarity requires, again, the simultaneous test of $2^{n-2}$ inequality constraints for each pair of practices: such inequality constraints are nothing other than the analytical expression of condition 3, rewritten in terms of the estimated coefficients associated with the strategy dummies $\left(\hat{\delta}_{l}\right)^{15}$.

\subsubsection{The indirect approach}

Given the great difficulties related to a direct test of complementarity, most authors have made recourse to an "indirect approach", testing the implications of complementarity instead of complementarity in itself. The great advantage of this approach consists in not requiring a performance measure; indeed, it focuses only on firm's inputs. Moreover, even when a direct test of complementarity is put forward (as in this study, see Section 5), a preliminary test of its indirect implications is still advisable.

A first implication to check, as highlighted by Athey and Stern (1998), is "clustering": if the implementation of one practice is likely to raise the marginal return on other practices, then the joint adoption of several practices should be preferred. It follows that, if a set of practices y is adopted more often together rather than separately, this can be interpreted as first evidence in favour of complementarity.

It is not difficult to identify the two main shortcomings of this approach: first of all, it only provides us with indicative, not conclusive, evidence in favour of complementarity, since it does not check for exogenous variables such as firm or industry characteristics. Moreover, focusing on count statistics, we overlook the continuous dimension and, with it, the possibility of a local (rather than global) complementarity, i.e. as long as the simple count statistics are looked at, no possibility exists of testing whether advantage in simultaneously carrying out different inputs emerges only conditionally to a certain expenditure threshold being overcome.

One way to deal with the first drawback is to rely on "exclusion restrictions". Let us assume an exogenous variable $z_{i}$ exists only affecting the adoption of practice $y_{i}$; in particular, assume $y_{i}\left(z_{i}\right)$ be non-decreasing in $\mathrm{z}_{\mathrm{i}}$. Any change of such an exogenous factor will directly influence only $\mathrm{y}_{\mathrm{i}}$, leaving $\mathrm{y}_{\mathrm{j}}$ unaffected unless the two practices directly interact with each other. In particular, if a relationship of complementarity exists between $y_{i}$ and $y_{j}, z_{i}$ will also (indirectly) affect the activity $\mathrm{y}_{\mathrm{j}}$. It follows that, if by means of exclusive adoption equations we are able to identify exclusive

\footnotetext{
${ }^{15}$ Cassiman \& Veugelers (2006) have applied this procedure to test complementarity between the two make and buy innovative decisions. Lokshin, Belderbos and Carree (2004) have shown how to extend this analysis to the cases of three and four inputs through a Likelihood-ratio (LR) testing procedure which is analogous to the Wald (distance) test procedure applied by Mohnen and Röller (2005) to the case of four (discrete) indicators of obstacles to innovation.
} 
drivers of one practice, we can then test complementarity as a significant, positive effect of this variable on the other practice (within a system of non-exclusive adoption equations).

This approach, defined by Athey and Stern (1998) as a "reduced-form test exploiting exclusion restrictions", allows us to check for both firm and industry characteristics; however, it cannot be applied whenever more than two practices are involved. This limit, theoretically highlighted by Arora (1996) and Athey and Stern (1998), clearly emerges in Cassiman and Veugelers (2002); in order to apply such a reduced-form test, these authors were forced to cut down the extent of their study to only two alternative knowledge sources (make and buy).

In addition, this procedure still uses discrete adoption decisions, leaving unsolved the second shortcoming of the cluster approach. The obvious consequence of such a limit is not only an efficiency loss, but also a much more severe constraint in our capacity to explore the (possible) local properties of complementarity (that is, the possibility that complementarity and substitutability relationships coexist, each of them holding over different subsets of the knowledge production function domain).

A different, continuous way of testing the implications of complementarity is by correlation analysis. Correlation analysis can be considered simply as the continuous version of clustering: if alternative inputs are complementary, then we would expect firms to exploit this opportunity, moving the input expenditure levels in the same direction. However, this apparently intuitive property has to be qualified:

a) indirect feedback effects through other practices have to be taken into account. Whenever more than two activities interact in generating an output, the sign (and magnitude) of pair-wise correlation coefficients is likely to be affected by the relationship linking the two analysed inputs to all the other practices they interact with. It follows that a negative correlation between two complementary practices $\left(y_{i}\right.$ and $\left.y_{j}\right)$ may emerge because of the dominant effect of a third practice $y_{k}$ that is a substitute for $y_{i}$ while being a complement for $y_{j}$;

b) firms' (observable and unobservable) heterogeneity has to be taken into account, as well. Innovative input relationships are in fact likely to be affected by external-to-the-strategy firm and industry characteristics.

Arora and Gambardella (1990) suggest solving problem (b) by estimating conditional (on observable) correlations between each pair of practices in lieu of the unconditional correlation coefficients computed on the original expenditure levels. To this aim, each (continuous measure of) a firm's investment decision $\mathrm{y}_{\mathrm{i}}$ has to be separately regressed upon a set $\mathrm{Z}$ of firm's characteristics and industry effects. The authors then apply the correlation analysis to the residuals of such estimates: positive conditional correlation coefficients are a necessary condition for two inputs to be 
complementary. However, this property only holds under a series of (quite strong) assumptions concerning the sources of heterogeneity and the shape of the underlying performance function:

1. the vector $\boldsymbol{\varepsilon}$ of the residuals has to be uncorrelated with the vector $\mathrm{Z}$ of exogenous variables characterising the model;

2. the variance-covariance matrix associated with $\boldsymbol{\varepsilon}$ is assumed to be diagonal, meaning that shocks to different practices are uncorrelated. "Systemic” shocks - that is, shocks associated with combinations of practices - are thus excluded by definition;

3. the payoff function $\Pi$ must be twice continuously differentiable and concave: $\Pi_{\mathrm{ii}} \leq 0$;

4. all the practices must be pair-wise complements: $\Pi_{\mathrm{ij}} \geq 0 \forall \mathrm{i} \neq \mathrm{j}$.

Moreover, this procedure does not solve problem (a): the possibility of indirect feedback effects acting through other endogenous practices ${ }^{16}$.

A way to get rid partially of these endogenous effects without giving up the indirect methodology consists in looking for threshold effects. If a gain exists in simultaneously performing two (or more) activities only when another endogenous practice is already carried out (or, more restrictively, it is already carried out at a certain level), then the risk exists that no systematic pattern emerges from aggregate pair-wise correlation analysis ${ }^{17}$, the overall coefficients being a misleading average of a relationship that is likely to vary depending on the value of the variables themselves. The threshold analysis iteratively re-computes the correlation coefficients over limited subsets of the innovative strategy domain obtained by imposing progressively higher minimum expenditure levels on the different practices. Possible differences between such threshold-constrained correlation coefficients and the overall ones will then signal the existence of indirect feedback effects.

\section{Data}

The empirical analysis has been carried out on firm-level data drawn from the third Italian CIS, conducted over a three-year period (1998-2000) by the Italian National Institute of Statistics (ISTAT). This survey is representative, at both sector and firm size level, of the entire population of Italian firms with more than 10 employees ${ }^{18}$. The dataset comprises a set of general information (main industry of affiliation, group belonging, sales, employment, export sales) next to a (much

${ }^{16}$ A fully satisfactory solution of problem (a) can only come from applying the broader concept of complementarity between groups of practices to the full set of activities interacting with each other in determining firm's performance, that is to turn to the direct approach (see previous section).

${ }^{17}$ Either unconditional or conditional.

${ }^{18}$ Thanks to a weighting procedure assigning weights according to the reciprocal of the probability of each observation to be sampled. This procedure, while correcting for sample selection, also ensures that each group of firms is properly represented and mitigates possible heteroskedasticity problems. 
larger) set of innovation variables measuring firms' innovativeness, economic and non-economic measures of the effects of innovation, subjective evaluations of factors hampering or fostering innovation, information sources, participation in cooperative innovation activities and access to public funding. The response rate was 53\%, determining a full sample size of 15,512 firms, 9,034 of which (58.24\%) belonging to the manufacturing sector we are focusing on. The manufacturing sample was then cleaned of outliers and firms involved in mergers or acquisitions during the previous three years, which would have biased our results. We thus ended up with 7,965 innovating and not-innovating firms.

The sub-sample of innovators was then selected following the standard practice of identifying innovators with those firms declaring that in the previous three years they had introduced product or process innovations, or, had started innovative projects (then dropped or stillto-complete at December $31^{\text {st }}$, 2000). The same definition has been implemented by ISTAT as a filter to avoid non-innovators having to plough through all the questions not relevant for them (with the risk of non-innovating firms not responding to the rest of the questionnaire). Thus, such firms, identified as non-innovators, were allowed to skip a large number of "innovation questions", leaving us with very little information about their propensity to innovate or to invest in innovative inputs. This means that the CIS database provides information relevant to this study only for innovative firms; therefore only these firms will be considered in the following analysis ${ }^{19}$, ending up with 3,045 firms. This sample, which has been used in the direct approach, has been furthermore reduced to 2,966 firms in the context of the indirect approach by keeping only firms investing in at least one of the four innovative inputs we will focus $\mathrm{on}^{20}$.

\subsection{The innovative variables}

As far as the input side of the innovative process is concerned, four sources of technological change have been used in this study: internal (in-house) R\&D (IR), external R\&D (ER, that is R\&D activities which have been outsourced to other firms or research institutes), embodied technological acquisitions (MAC, that is innovative investment in plants, machinery and equipment) and disembodied technological acquisitions (TA, including licensing agreements, software, projects and

${ }^{19}$ Our purpose being that of analysing the nature of the interactions taking place within the innovative process (and not, for example, the effect of different inputs in determining the probability of innovating), this data limitation does not raise a problem of selection bias. Since we are interested in the internal mechanism of the innovative process, we have to focus on a randomly selected sample of innovative firms (that is, randomness must hold within the innovative sub-sample, not in comparison with the non-innovative one where such a mechanism is obviously absent).

${ }^{20}$ The CIS adopts a wide definition of innovative inputs, including not only R\&D and technological acquisitions (both embodied and disembodied), but also training, marketing of innovative products, design and other activities classified as preliminary to the introduction of new (or substantially improved) products or processes. 
consultancies). These four inputs have been simultaneously analysed in order to cover a large part of total innovative expenditure (89\%) without simplifying the heterogeneity within it.

Besides innovative inputs, the CIS also provides us alternative measures of innovative output: the introduction of product innovations (Product), the introduction of process innovations (Process) and the share of firm's total sales due to sales of new products (Turninn). While the first two indicators are discrete (0/1), the third is the only continuous measure we have at our disposal for assessing the intensity of innovation. Table 1 provides a list of the innovative inputs and outputs.

Table 1: List and definitions of the innovative variables.

\begin{tabular}{l|l}
\hline \multicolumn{1}{l}{ Innovative input variables: continuous level } \\
\hline $\operatorname{logIR}$ & Natural log of internal R\&D expenditure in 2000. \\
\hline $\operatorname{logER}$ & Natural log of external R\&D expenditure in 2000. \\
\hline logMAC & Natural log of investments in machinery and equipment in 2000. \\
\hline logTA & Natural log of technological acquisitions in 2000. \\
\hline Innovative input variables: discrete level \\
\hline IRd & Dummy=1 if firm invests in internal R\&D, 0 otherwise. \\
\hline ERd & Dummy=1 if firm invests in external R\&D, 0 otherwise. \\
\hline MACd & Dummy=1 if firm invests in machinery and equipment, 0 otherwise. \\
\hline TAd & Dummy=1 if firm invests in disembodied tech. acquisitions, 0 otherwise \\
\hline Innovative output variables \\
\hline Product & Dummy=1 if firm has realised product innovations. \\
\hline Process & Dummy=1 if firm has realised process innovations. \\
\hline logTurninn & Natural log of the share of firm's total sales due to sale of new products \\
\hline $\begin{array}{l}\text { Notes: } \\
- \\
\text { all the expenditure variables are expressed in thousands of Euros; } \\
\text { the natural logs of the input expenditures were computed after adding } 1 \text { to the original variables: thanks to this } \\
\text { device, zeros stay as zeros, keeping their interpretation unchanged. }\end{array}$ \\
\hline
\end{tabular}

\subsection{The control variables}

Both the input and the output side of the innovative process are likely to be affected by firm characteristics such as size, group belonging or international openness as well as by the sectoral, environmental and institutional framework the firm operates in. The questionnaire structure, providing us with general firm-level information, allows us to check for the effects such factors produce on either firms' investment decisions or innovative performance, while excluding them as potential indirect drivers of the complementarity (substitutability) relationships we are trying to assess. Table 2 briefly describes the variables used in the empirical analysis, grouping them in two sub-categories: "general firm characteristics” and "innovation-relevant information”. 
Table 2: List and definitions of the control variables.

\begin{tabular}{|c|c|}
\hline \multicolumn{2}{|c|}{ General firm characteristics } \\
\hline logEmp & Natural log of firm’s employees at December 31 $1^{\text {st }}, 2000$. \\
\hline logTurn & Natural log of firm’s turnover at December 31 $1^{\text {st }} 2000$. \\
\hline logImmat & Natural log of firm’s investments in tangible assets in 2000. \\
\hline logExpint & Natural log of export intensity (turnover from exportations/turnover) in 2000. \\
\hline mkt_extent & $\begin{array}{l}\text { Prevailing (geographical) market extent; it ranges from } 0 \text { (provincial) to } 7 \\
\text { (extra-UE). }\end{array}$ \\
\hline Group & Belonging to an industrial group (dummy variable). \\
\hline Industry & 23 Industry dummies (two-digit ATECO 91). \\
\hline High-tech & $\begin{array}{l}\text { Dummy=1 if the firm belongs to a medium-high or high-tech sector; } 0 \\
\text { otherwise. }\end{array}$ \\
\hline pavitt1-pa & $\begin{array}{l}\text { Four dummies mapping the three-digit ATECO } 91 \text { codes onto the four } \\
\text { categories identified by Pavitt's (1984) taxonomy: science-based, supplier- } \\
\text { dominated, scale-intensive and specialised supplier firms. }\end{array}$ \\
\hline \multicolumn{2}{|c|}{ Innovative-relevant information } \\
\hline $\operatorname{logRtot}$ & Natural log of tot \\
\hline $\mathrm{d} 1-\mathrm{d} 4$ & $\begin{array}{l}\text { Number of innovative inputs the firm has invested in (from } 0 \text { to } 4 \text { ). } \\
\text { Dummies expressing the number of innovative inputs the firm has invested in: } \\
d_{n}=1(\text { if group }=n) \text {. }\end{array}$ \\
\hline $\begin{array}{l}\text { co } \\
\text { comkasic }\end{array}$ & $\begin{array}{l}\text { Participation in cooperative innovative activities (dummy) } \\
\text { Cooperation with universities and/or research institutes (dummy). } \\
\text { Cooperation with suppliers, customers and/or competitors (dummy). }\end{array}$ \\
\hline avgbasic & $\begin{array}{l}\text { Importance of basic information sources relative to market sources } \\
\text { (avgbasic/avgmkt). } \\
\text { Average importance of basic sources of information (universities, research inst., } \\
\text { conferences) for the innovative process: from } 0 \text { to } 3 \text {. } \\
\text { Average importance of market information sources (competitors, customers, } \\
\text { suppliers) for the innovative process: from } 0 \text { to } 3 \text {. }\end{array}$ \\
\hline funding & Dummy = 1 if the firm has received public support for innovation, 0 otherwise. \\
\hline $\begin{array}{l}\text { hurdle } \\
\text { hinternal }\end{array}$ & $\begin{array}{l}\text { Dummy = } 1 \text { if the firm has faced some kind of obstacle to innovation. } \\
\text { Average relevance of internal hurdles (lack of information, lack of skilled } \\
\text { personnel, organisational rigidities): from } 0 \text { to } 3 \text {. } \\
\text { Average relevance of financial hurdles (excessively high economic costs and/or } \\
\text { risks, no sources of financial support): from } 0 \text { to } 3 \text {. }\end{array}$ \\
\hline pro_formal & $\begin{array}{l}\text { Dummy = } 1 \text { if patents, copyright or registration of brands are perceived by the } \\
\text { firm as useful protection methods. }\end{array}$ \\
\hline pro_strategic & $\begin{array}{l}\text { crecy, complexity or lead time are perceived by the firm as } \\
\text { ethods. }\end{array}$ \\
\hline pdt_quality & ative effect on product quality: from 0 to 3. \\
\hline mkt_novelty & ew to the market. \\
\hline pdt_out & $\begin{array}{l}\text { my = } 1 \text { if product innovations have been mainly realised by external-to- } \\
\text { irm subjects: other firms and/or research institutes. }\end{array}$ \\
\hline otherinn & Dummy = 1 if the firm realised managerial, strategic or organiz. innovations. \\
\hline \multicolumn{2}{|c|}{$\begin{array}{l}\text { Notes: } \\
\text { - } \quad \text { all the expenditure variables are expressed in thousands of Euros; } \\
\text { - } \quad \text { the number of innovative inputs (group) refers only to the four innovative activities we are explicitly interested } \\
\text { in: internal and external research, embodied and disembodied technological acquisitions. }\end{array}$} \\
\hline
\end{tabular}




\section{The indirect approach: correlation analysis}

\subsection{Unconditional correlation analysis}

As a starting point, let us compute the correlation coefficients among the innovative inputs at both the continuous and discrete levels (see tables 3 and 4). As was highlighted in Section 2.3.2, this unconditional analysis is a first step in view of the conditional one (see next Section 4.2). As can be seen, while positive correlations (suggesting complementarities) prevail, the relationship between R\&D (both internal and external) and embodied technological acquisitions (MAC) significantly emerges as being negative, pointing towards the substitutability hypothesis.

Table 3: Unconditional correlation coefficients (continuous level)

\section{Table 4: Unconditional correlation (discrete level)}

\begin{tabular}{|c|c|c|c|c|c|c|c|c|c|}
\hline $\log \mid R$ & $\begin{array}{l}\text { logIR } \\
1.000\end{array}$ & $\log E R$ & $\log M A C$ & $\log T A$ & IRd & $\begin{array}{l}\text { IRd } \\
1.000\end{array}$ & ERd & MACd & TAd \\
\hline $\log E R$ & $\begin{array}{l}\mathbf{0 . 3 0 5 * * *} \\
(0.000)\end{array}$ & 1.000 & & & ERd & 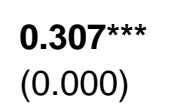 & 1.000 & & \\
\hline $\log M A C$ & $\begin{array}{l}-\mathbf{0 . 0 6 9} 9^{* * *} \\
(0.000)\end{array}$ & $\begin{array}{l}-0.024 \\
(0.101)\end{array}$ & 1.000 & & MACd & $\begin{array}{l}-0.272^{\star * *} \\
(0.000)\end{array}$ & $\begin{array}{l}-0.07^{* * *} \\
(0.000)\end{array}$ & 1.000 & \\
\hline $\log T A$ & 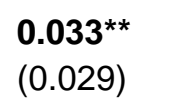 & $\begin{array}{l}\mathbf{0 . 0 7 2 * * *} \\
(0.000)\end{array}$ & $\begin{array}{l}\mathbf{0 . 0 3 4} \\
(0.019)\end{array}$ & 1.000 & TAd & $\begin{array}{l}-0.01 \\
(0.589)\end{array}$ & $\begin{array}{l}\mathbf{0 . 0 6 2 * \star *} \\
(0.001)\end{array}$ & $\begin{array}{l}0.004 \\
(0.816)\end{array}$ & 1.000 \\
\hline
\end{tabular}

The comparison of the two tables, however, suggests the presence of a negative bias operating through exclusive investment decisions; in fact, the continuous-level negative coefficients (those between IR and MAC and between ER and MAC) become higher and more significant when we shift to the discrete level, while the positive ones (with the sole exception of that between IR and $\mathrm{ER}^{21}$ ) shrink in value and significance until changing sign in the case of the correlation between IR and TA. Thus our guess is that exclusive choices may have played a role in driving the negative

\footnotetext{
${ }^{21}$ This correlation stays almost unchanged when skipping from one level to the other; an explanation for this should be looked for in the relative occurrences of the two inputs, mainly appearing together in the sample (86.25\% of ER-investing firms are active in IR activities too).
} 
correlations that have emerged from tables 3 and 4. The relative importance of such exclusive choices (together with a comparison of each input's relative weight compared to total innovative expenditures) is displayed in the following table.

Looking at Table 5, we can easily compute that almost half of the sample (44.76\%) invests exclusively in only one innovative input, a choice that seems to play a particularly important role as far as investments in plants, machinery and equipment (MAC) are concerned. These statistics confirm the existence of a negative correlation bias acting through such large shares of exclusive investment strategies. This negative bias, as well as the possible local properties of complementarity, will be checked out through the threshold analysis performed in Section 4.3.

Table 5: Share of single innovative inputs in total innovative expenditure.

\begin{tabular}{|c|c|c|c|c|c|}
\hline & IR & ER & MAC & TA & Res \\
\hline $\begin{array}{l}\% \text { of } 0 \text {-expenditure firms within each } \\
\text { category }\end{array}$ & 41.98 & 77.68 & 20.43 & 79.03 & 46.59 \\
\hline $\begin{array}{l}\% \text { of firms investing in this category } \\
\text { only (over the full sample) }\end{array}$ & 11.26 & 1.04 & 30.51 & 1.95 & $\mathbf{0}$ \\
\hline \multicolumn{6}{|c|}{ Share in total innovative expenditure (\%): } \\
\hline Mean & 29.13 & 4.64 & 48.75 & 4.51 & 12.97 \\
\hline Median & 11.13 & $\mathbf{0}$ & 45.68 & $\mathbf{0}$ & 1.47 \\
\hline Standard deviation & 34.99 & 14.25 & 40.48 & 15.45 & 20.34 \\
\hline \multicolumn{6}{|c|}{$\begin{array}{l}\text { The last category (Res) includes all the innovative expenditures other than the } 4 \text { analysed inputs: training, marketing } \\
\text { of innovative products, design and other activities classified as preliminary to the introduction of new - or } \\
\text { substantially improved - products or processes. The fraction of firms only investing in this category is zero by sample } \\
\text { construction (check Section 3). }\end{array}$} \\
\hline
\end{tabular}

\subsection{Conditional correlation analysis}

As discussed in Section 2.3.2, the procedure adopted to check for firms' observables is the following: first, the continuous measure of each innovative input is separately regressed on a selected set of explanatory variables; then, the correlation coefficients among the residuals of the four equations are computed. This procedure, however, requires consistent estimates of each input equation. Since our four dependent variables are lower-censored at zero (see Table 5), linear regression methods must be excluded. Hence, four separate Tobit models were estimated, explaining firms' innovative investment decisions as functions of both general and innovation- 
specific firm characteristics and industry effects (see Table 2) ${ }^{22}$. Table 6 reports the conditional correlation coefficients.

The results do not appear substantially different from the unconditional ones (Table 3). In particular, they confirm the negative correlations between embodied technological acquisitions and the two forms of R\&D, thus strengthening the evidence in favour of the substitutability hypothesis. However, overall correlations in Table 6 may be affected by: 1) the negative bias due to exclusive input choices discussed in the previous Section 4.1;2) non linearities and threshold effects which deserve further investigation.

Table 6: Conditional correlation coefficients (residuals from four separate Tobit estimations).

\begin{tabular}{|c|c|c|c|c|}
\hline resIR & $\begin{array}{l}\text { resIR } \\
1.0000\end{array}$ & resER & resMAC & resTA \\
\hline resER & 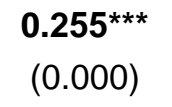 & 1.0000 & & \\
\hline resMAC & $\begin{array}{c}-\mathbf{0 . 1 8 5 * * *} \\
(0.000)\end{array}$ & $\begin{array}{c}-\mathbf{0 . 1 0 2 * * *} \\
(0.000)\end{array}$ & 1.000 & \\
\hline resTA & 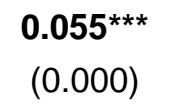 & $\begin{array}{c}\text { 0.193*** } \\
(0.000)\end{array}$ & $\begin{array}{c}0.009 \\
(0.457)\end{array}$ & 1.000 \\
\hline \begin{tabular}{ll}
\multicolumn{2}{ll}{ Notes: } \\
- & Ken \\
- & Con \\
\end{tabular} & $\begin{array}{l}\tau_{\mathrm{b}} \text { correlatio } \\
\text {-corrected } \mathrm{p}\end{array}$ & $\begin{array}{l}\text { efficients; } \\
\text { lues in brach }\end{array}$ & *** signif & nt at $1 \%$; \\
\hline
\end{tabular}

\subsection{Conditional correlation analysis at different levels of internal R\&D.}

Consistently with the hypothesis of a pivotal role of internal R\&D (IR) in generating and supporting firms' absorptive capacity (see Section 2), we test here the effect that higher IR may have on the interactions between the four inspected innovative inputs. Does IR play a "switching" role in affecting complementarity among innovative inputs, once we have accounted for firm heterogeneity?

In order to answer this question the four input equations were sequentially estimated on the progressively smaller sub-samples of firms obtained by imposing step-by-step higher threshold levels to IR. More precisely, Tobit models were estimated for $\operatorname{logER}$, logMAC and logTA since

${ }^{22}$ The inclusion of all the relevant controls generated a multicollinearity problem (as expected); this was solved by applying the Maximum Likelihood factor analysis to the highly correlated regressors. Results from the factor analysis and from the 4 Tobit estimates are available on request. 
their lower-censored nature is not affected by the truncation of the IR variable; this last input, instead, was estimated by a standard truncated regression model able to correct for the endogenous truncation of the dependent variable. Kendall's correlation coefficients between the residuals of such estimates were then computed for each IR decile (starting from the median, which is the first decile to be larger than zero): these coefficients are given in Table 7.

The first striking result concerns the obvious threshold effect characterising the correlation between IR and embodied technological acquisitions (MAC): although the overall correlation coefficients suggested substitutability (see previous Tables 3, 4 and 6), the two activities tend to move in the same direction once a threshold level for in-house R\&D has been overcome (IR>IR50). In other words, complementarity effects from the simultaneous investment in internal $\mathrm{R} \& \mathrm{D}$ and embodied technical change are conditional to having undertaken a minimum amount of IR activities. Moreover, it can be noticed that the correlation coefficients increase monotonically as long as higher $R \& D$ thresholds are imposed ${ }^{23}: R \& D$ seems to have the unique “catalysing” capacity of accelerating the "reactions" taking place within the innovative process, improving the quality of the other inputs it interacts with.

This catalysing effect is also confirmed by the analysis of pair-wise correlations which do not directly involve internal research. Indeed, referring to the last three columns of Table 7, it can be seen that, requiring that internal $R \& D$ be larger than 0 , the correlation between external research (ER) and embodied technological acquisitions (MAC) - which was significantly negative for the whole sample - becomes positive and significant, rising in absolute value with rising threshold levels of IR (up to the $80^{\text {th }}$ percentile). The same is true for the correlation between embodied and disembodied technological acquisitions, also switching from non significant to significant positive values.

This is a first validation of the hypothesis that synergies between innovative inputs are not exogenous and automatic: it is internal $R \& D$ that creates the precondition allowing firms to enjoy complementarity effects. It has to be underlined that this catalysing effect is specific to R\&D and is not the consequence of imposing a minimum threshold level on any innovative input. In Table A1 in the Appendix, we report the results we have obtained by imposing threshold levels on the quantitatively most relevant alternative to IR: embodied technological acquisitions (MAC). As can be seen, no unambiguous evidence of MAC in generating complementarity emerges.

${ }^{23}$ At least up to the $80^{\text {th }}$ percentile; after that, the correlation coefficient - albeit remaining positive and highly significant - shows a decrease in magnitude, suggesting the possibility of decreasing returns in complementarity. 
Table 7: Conditional 4-input correlation coefficients by IR deciles.

\begin{tabular}{|c|c|c|c|c|c|c|}
\hline & $\begin{array}{l}\text { Correlation } \\
(\log I R-\log E R)\end{array}$ & $\begin{array}{l}\text { Correlation } \\
\text { (logIR-logMAC) }\end{array}$ & $\begin{array}{l}\text { Correlation } \\
(\log I R-\log \mathrm{TA})\end{array}$ & $\begin{array}{l}\text { Correlation } \\
\text { (logER-logMAC) }\end{array}$ & $\begin{array}{l}\text { Correlation } \\
(\operatorname{logER}-\log \mathrm{TA})\end{array}$ & $\begin{array}{c}\text { Correlation } \\
(\log M A C-\log T A)\end{array}$ \\
\hline $\begin{array}{l}\text { Full samp. } \\
\text { (2966 obs) }\end{array}$ & 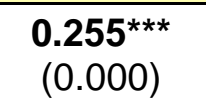 & $\begin{array}{c}-\mathbf{0 . 1 8 5 * * *} \\
(0.000)\end{array}$ & 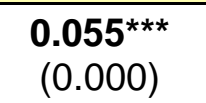 & $\begin{array}{c}-\mathbf{0 . 1 0 2 * * *} \\
(0.000)\end{array}$ & $\begin{array}{c}\text { 0.193*** } \\
(0.000)\end{array}$ & $\begin{array}{c}0.009 \\
(0.457)\end{array}$ \\
\hline $\begin{array}{c}\mathbf{I R}>\mathbf{0} \\
(1721 \text { obs })\end{array}$ & $\begin{array}{c}\mathbf{0 . 0 5 3 * * *} \\
(0.001)\end{array}$ & $\begin{array}{l}0.009 \\
(0.574)\end{array}$ & $\begin{array}{c}0.028 \\
(0.077)\end{array}$ & $\begin{array}{l}\mathbf{0 . 0 3 2 * *} \\
(0.045)\end{array}$ & $\begin{array}{c}\mathbf{0 . 2 0 2 * * *} \\
(0.000)\end{array}$ & $\begin{array}{c}\mathbf{0 . 1 1 4}{ }^{* * *} \\
(0.000)\end{array}$ \\
\hline $\begin{array}{l}\text { IR > IR50 } \\
(1481 \text { obs })\end{array}$ & $\begin{array}{c}\mathbf{0 . 0 9 5 * * *} \\
(0.000)\end{array}$ & $\begin{array}{l}0.040 \text { ** } \\
(0.020)\end{array}$ & $\begin{array}{c}\mathbf{0 . 0 6 2 * * *} \\
(0.000)\end{array}$ & $\begin{array}{l}\mathbf{0 . 0 3 3}^{*} \\
(0.054)\end{array}$ & $\begin{array}{c}\mathbf{0 . 1 6 7 * * *} \\
(0.000)\end{array}$ & $\begin{array}{c}\mathbf{0 . 1 2 6 * * *} \\
(0.000)\end{array}$ \\
\hline $\begin{array}{l}\text { IR }>\text { IR60 } \\
(1184 \text { obs })\end{array}$ & $\begin{array}{c}0.156^{* * *} \\
(0.000)\end{array}$ & $\begin{array}{c}\mathbf{0 . 0 7 3 * * *} \\
(0.000)\end{array}$ & $\begin{array}{c}0.094^{* * *} \\
(0.000)\end{array}$ & $\begin{array}{l}\mathbf{0 . 0 4 8 * *} \\
(0.012)\end{array}$ & $\begin{array}{c}\mathbf{0 . 1 6 3}{ }^{* * *} \\
(0.000)\end{array}$ & $\begin{array}{c}\mathbf{0 . 1 2 8 * * *} \\
(0.000)\end{array}$ \\
\hline $\begin{array}{c}\text { IR }>\text { IR70 } \\
\text { (887 obs) }\end{array}$ & $\begin{array}{c}\mathbf{0 . 1 9 1 * * *} \\
(0.000)\end{array}$ & $\begin{array}{c}\mathbf{0 . 0 8 4 * * *} \\
(0.000)\end{array}$ & $\begin{array}{c}\mathbf{0 . 1 2 4} 4^{* * *} \\
(0.000)\end{array}$ & $\begin{array}{c}\mathbf{0 . 0 5 4 * * *} \\
(0.004)\end{array}$ & $\begin{array}{c}\mathbf{0 . 1 3 6 * * *} \\
(0.000)\end{array}$ & $\begin{array}{c}\mathbf{0 . 1 3 8 * * *} \\
(0.000)\end{array}$ \\
\hline $\begin{array}{c}\text { IR > IR80 } \\
\text { (584 obs) }\end{array}$ & $\begin{array}{c}\mathbf{0 . 1 9 6 * * *} \\
(0.000)\end{array}$ & $\begin{array}{c}\mathbf{0 . 0 9 7 * * *} \\
(0.000)\end{array}$ & $\begin{array}{c}0.170^{* * *} \\
(0.000)\end{array}$ & $\begin{array}{l}\mathbf{0 . 0 6 4}{ }^{* *} \\
(0.021)\end{array}$ & $\begin{array}{c}\mathbf{0 . 1 4 5 * * *} \\
(0.000)\end{array}$ & $\begin{array}{l}\mathbf{0 . 1 6 6 * * *} \\
(0.000)\end{array}$ \\
\hline $\begin{array}{c}\text { IR }>\text { IR90 } \\
(296 \text { obs })\end{array}$ & $\begin{array}{c}\mathbf{0 . 2 5 6 * * *} \\
(0.000)\end{array}$ & $\begin{array}{l}\mathbf{0 . 0 7 7 ^ { * * }} \\
(0.047)\end{array}$ & 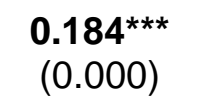 & $\begin{array}{c}0.053 \\
(0.175)\end{array}$ & $\begin{array}{c}\mathbf{0 . 1 6 4} \text { *** } \\
(0.000)\end{array}$ & $\begin{array}{c}\mathbf{0 . 1 6 4} 4^{* * *} \\
(0.003)\end{array}$ \\
\hline
\end{tabular}

\section{The performance analysis}

The output of the indirect approach does not allow us to draw definite conclusions as to the nature of innovative input relationships. First of all, as Arora (1996) remarked, a positive and significant correlation is a necessary but not a sufficient condition in order for two inputs to be complements: it is complementarity which implies, under some conditions, positive correlation while the reverse is not always true. Hence, the previous section's results - showing positive correlation between the four analysed innovative inputs once a threshold level for IR has been overcome - do not necessarily demonstrate that such co-movements positively affect firms' innovative performance. A performance analysis must be carried out in order for such a conclusion to be fully supported.

A first, preliminary step we will make in this direction (see next Section 5.1) consists in checking if there is an a priori advantage - in terms of innovative performance - in raising the number of innovative inputs a firm decides to invest in. If the innovation production function is indeed supermodular in all its elements, simultaneously investing in more than one innovative input should always be preferred to exclusive alternatives, whatever the involved inputs are. In the words of Athey and Stern (1998), a "clustering effect” should emerge (see Section 2.3.2). While Section 5.2 will extend the analysis in search of a peculiar catalysing role for IR, it is in Section 5.3 that we 
will enter into the heart of the matter, exploring the innovative performance associated with combinations of alternative innovative inputs. In that section the complementarity and substitutability hypotheses will be directly tested on the estimated coefficients associated with the discretely-defined exclusive innovative input strategies.

\subsection{Looking for the "clustering effect"}

The descriptive evidence reported in Table 8 seems to confirm a generic (unconditional) advantage in increasing the number of innovative inputs, whatever measure of innovative output is considered, either discrete (first three columns) or continuous (last column).

Table 8: Innovative performance and number of innovative inputs.

\begin{tabular}{|c|c|c|c|c|}
\hline Group & $\begin{array}{c}\text { Process } \\
\text { innovators (\%) }\end{array}$ & $\begin{array}{c}\text { Product } \\
\text { innovators (\%) }\end{array}$ & $\begin{array}{l}\text { Prod. and Proc. } \\
\text { innovators (\%) }\end{array}$ & $\begin{array}{c}\text { Average Turninn } \\
\text { (2000) }\end{array}$ \\
\hline $\begin{array}{l}\text { no innovative } \\
\text { input }\end{array}$ & 46.84 & 68.35 & 25.32 & $\begin{array}{c}25.87 \\
(28.80)\end{array}$ \\
\hline 1 innovative input & 71.16 & 60.02 & 37.50 & $\begin{array}{c}22.76 \\
(28.49)\end{array}$ \\
\hline 2 innovative inputs & 74.58 & 81.11 & 60.44 & $\begin{array}{c}31.60 \\
(29.21)\end{array}$ \\
\hline 3 innovative inputs & 76.27 & 87.63 & 67.14 & $\begin{array}{c}35.85 \\
(28.43)\end{array}$ \\
\hline 4 innovative inputs & 85.82 & 95.52 & 82.09 & $\begin{array}{c}41.25 \\
(30.05)\end{array}$ \\
\hline Total (3045 firms) & 73.14 & 73.27 & 51.56 & $\begin{array}{c}28.71 \\
(29.36)\end{array}$ \\
\hline
\end{tabular}

The probability of introducing either product or process innovations (as well as the probability of realising both of them) monotonically increases as long as the number of the adopted innovative inputs goes from 1 to 4 . This result is confirmed when a continuous measure (Turninn) of innovative performance is adopted (last column of Table 8).

However, this preliminary evidence needs to be confirmed by a conditional analysis checking not only for firm's characteristics and industry effects (as in the previous section), but also for the firm's overall innovative expenditure (logRtot); in fact, the above-presented results might be merely due to the higher level of total innovative expenditures that is likely to be associated with a 
higher number of innovative inputs ${ }^{24}$. With these purposes in mind, we have estimated a bivariate probit model allowing us to check for firm's characteristics, industry specific effects and total innovation expenditures $(Z)$, while checking for the effect the number of innovative inputs exerts on the probability of introducing either a product or process innovation (here allowed to be correlated with each other, in order to take into account the simultaneous nature of the innovation decisions concerning new products and new processes). In analytical terms, we estimated the following model:

$$
\begin{cases}y_{1}^{*}=\sum_{n=1}^{4} d_{n} \cdot \beta_{1 n}+Z \gamma_{1}+\varepsilon_{1} & y_{1}=1 \text { if } y_{1}^{*}>0, y_{1}=0 \text { otherwise; } \\ y_{2}^{*}=\sum_{n=1}^{4} d_{n} \cdot \beta_{2 n}+Z \gamma_{2}+\varepsilon_{2} & y_{2}=1 \text { if } y_{2}^{*}>0, y_{2}=0 \text { otherwise; }\end{cases}
$$

where the same set of exogenous factors $Z$ was checked for in the two equations; $\varepsilon_{1}$ and $\varepsilon_{2}$ are joint normal with means zero, variances one and correlation $\rho\left(y_{1}^{*}\right.$ and $y_{2}^{*}$ being the latent variables underlying the two binary outcomes we observe $)^{25}$.

Four distinct dummies $d_{n}$ were introduced as regressors allowing for different intercepts to correspond to different numbers of innovative inputs ${ }^{26}$. Model (11) was then estimated through maximum likelihood on the sub-sample of innovators reporting positive total innovative expenditures (3,045 firms, see Section 3) ${ }^{27}$.

As can be observed in Table 9, the likelihood ratio test of $\rho=0$ allows us to strongly reject the null of no correlation between the error terms; this result supports the need for a bivariate probit model of product and process innovation ${ }^{28}$. Consistently with the unconditional analysis, estimates

${ }^{24}$ By the same token, larger firms may take advantage of scale economies in the overall innovative process. The following conditional analysis will then check for (non-linear) size effects as well.

${ }^{25}$ This model collapses to two separate probit models for $y_{1}$ and $y_{2}$ (respectively, product and process innovation) when the error correlation $\rho=0$.

${ }^{26}$ The inclusion of the four distinct group dummies instead of a sole variable ranging from 0 to 4 allows us to check for (possible) decreasing returns or non-monotonic effects. Interactions between each dummy and total innovative expenditures were tested too, turning out to be never significant.

${ }^{27}$ As far as the control regressors are concerned, all the explanatory variables included in Table 2 were initially inserted; then, only significant variables in at least one of the two equations were selected, through a step-wise procedure.

${ }^{28}$ As far as the effects of firm's characteristics are concerned, it is interesting to observe how they differ according to the innovation output. Thus, for example, it seems that firms with a wider geographical market are more likely to be product innovators but less likely to generate process innovations. The same happens for the existence of effective legal protection measures (pro_formal) allowing the firm to appropriate the benefits of innovation. The effectiveness of such mechanisms significantly raises the probability of introducing product innovation, while it seems to make process innovation less likely. As far as firm's size is concerned, no evidence of scale economies emerges with regard to product innovation, while larger firms seem to be in a better position to provide process innovation, at least above a given threshold. The remaining controls seem to affect just one of the two innovative activities. This is the case of group belonging (negatively affecting the probability of introducing process innovations while not being significant in the 
in Table 9 confirm that the probability of introducing an innovation (either product or process) monotonically increases in the number of innovative inputs.

Table 9: Bivariate probit estimates of product and process innovation.

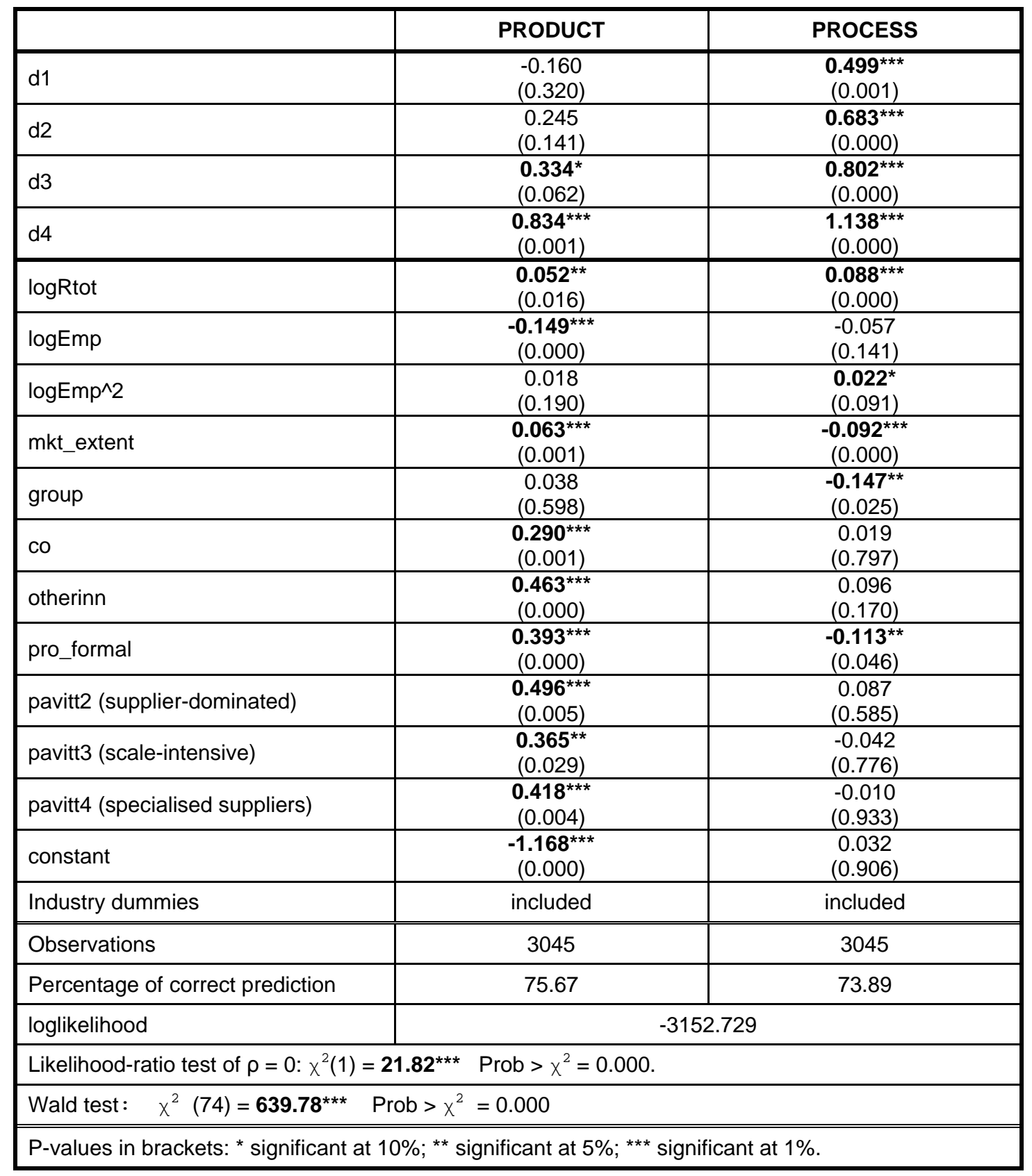

However, this unambiguous result in favour of complementarity does not find support once a continuous measure of innovative performance is taken into account (logTurninn). Both a generalised sample selection model and a truncated model were estimated and the four dummies d1-

first equation), while both firm participation in cooperative innovative activities and the introduction of organizational, managerial and/or marketing innovations in the previous three years turns out to raise significantly only the firm's propensity to generate product innovations. 
$\mathrm{d} 4$ never turned out to be significant ${ }^{29}$. In other words, it seems that the positive effect generated by an indiscriminate increase in the number of innovative inputs dries up in raising the probability of innovating, without affecting its intensity. However, consistently with what we did in Section 4.3, we still have to investigate the possible distinct role of internal research.

\subsection{A special role for internal R\&D?}

As a first step, the hypothesis of a specific role of IR, suggesting its "catalysing” ability to activate and amplify synergies between otherwise alternative or independent innovative inputs, will be tested through the estimation of the innovation intensity equation (logTurninn) on the two subsamples identified by the firms' choice to invest or not in IR.

In doing so, we must first of all deal with the limitation of our dependent variable, which only accounts for the market performance associated with product innovations; it follows that the quite large percentage of firms (26.73\%) reporting no innovative turnover mainly represents firms realising process innovations only, the intensity of which we cannot account for ${ }^{30}$. Consistently with this interpretative argument, the sole sub-sample of firms declaring they had introduced product innovation $^{31}$ was used. However, a generalised selection model (Tobit type 2) was estimated on the full sample in order to check for the possible bias arising from the selection we operated ${ }^{32}$. The null of independent equations (that is, absence of sample selection) was never rejected, so we used truncated models, regressing the share of innovative turnover on the four dummies identifying the number of innovative inputs and the usual set of exogenous factors, conditionally on the dependent variable being larger than zero (2231 observations). Table 10 (column a) reports the results from the overall truncated estimate, together with the sample selection test obtained by the generalised selection model. The same model was then separately estimated on the two sub-samples identified by a firm's decision to perform IR or not (respectively 1482 and 749 observations, columns c and b). Interestingly enough, the possible advantage firms may get from simultaneously performing

${ }^{29}$ Such estimates, together with a more detailed description of both the econometric methodology and its results, are discussed in the next Section 5.2 (see Table 10, column (a)).

${ }^{30}$ The risk is that of underestimating the effect that innovative inputs can produce on the intensity of innovation simply because of firms directing such investments towards a different aim. Moreover, this problem is likely to be exacerbated by a separate analysis of IR-investing and non-IR-investing firms, since IR is much more correlated to product innovation than the other inputs are (see Parisi et al., 2006), thus making the risk of underestimating the returns on the number of innovative inputs more severe when the sample of non-IR-investing firm is analysed. Proof of this is that the percentage of firms reporting zero innovative turnover reaches its minimum (13.89\%) when IR-investing firms only are considered, while reaching its maximum (43.43\%) when computed on the residual sample. When a firm's decision to invest or not in embodied technological acquisitions is analysed, the percentages become, respectively, 22.92 and 27.84 .

${ }^{31}$ That is, firms having realised either product innovation only or product and process innovation.

${ }^{32}$ Not reported, available upon request. 
different innovative inputs only emerges for the IR-investing sub-sample. Once checked for total innovative expenditure (which is, not surprisingly, always significantly positive), the dummy variables turn out to be negative and not significant for either the full sample or the sub-sample of firms not investing at all in IR, while switching to positive and - in two out of three cases significant values once IR-investing firms are focused $\mathrm{on}^{33}$.

Such an encouraging result, however, still seems incomplete: firstly because a direct, complete comparison of the two sub-samples is not possible, in that the four-input and the one-input cases are obviously excluded from the non-IR- and the IR-investing sub-samples respectively. Secondly, the "discovered" gain associated with simultaneously pursuing multiple innovative activities turns out to be significant only from the third input onwards (that is, starting from $\mathrm{d} 3$ in column c). Thirdly, previous analysis in Section 4 suggested that the catalysing role of IR may depend on something more than a simple binary decision; indeed, according to the indirect approach results, it is the increasing level of IR that makes complementarity relevant.

Accordingly, column (d) in Table 10 reports the result of an additional estimate where interactions of IR with each of the four dummies identifying the number of innovative inputs were included, in order to check for the ways different IR levels affect a firm's advantage in simultaneously investing in more than one innovative input. Thus, the effect of investing in a number $n$ of inputs (with $n$ going from one to three) on logTurninn is now assumed to be no longer constant over the sample, but depending on firms’ IR expenditures:

$\frac{\text { Ilturninn }_{i}}{\partial d n_{i}}=\beta_{d n}+\beta_{d n I R} \cdot \log I R_{i}$

which collapses to:

$$
\frac{\text { Dlturninn }_{i}}{\partial d 4_{i}}=\beta_{d 4 I R} \cdot \log I R_{i} \quad \text { for } \mathrm{n}=4^{34}
$$

Thanks to this methodology, we are now able to check for the existence of threshold effects analogous to the ones we discovered through the indirect approach (see Section 4.3).

\footnotetext{
${ }^{33}$ No significant differences emerge in the role control variables play over the three samples.

${ }^{34}$ We would otherwise have allowed for a non-zero coefficient to be associated with $\mathrm{d} 4$ in the case of IR=0, in spite of the fact that the two events (that is, a four-input investment decision and no internal research) are obviously incompatible with each other.
} 
Table 10: Truncated regressions of logTurninn on innovative input dummies.

\begin{tabular}{|c|c|c|c|c|}
\hline & $\begin{array}{c}\text { (a) } \\
\text { Full sample }\end{array}$ & $\begin{array}{c}\text { (b) } \\
I R d=0\end{array}$ & $\begin{array}{c}\text { (c) } \\
\mid R d=1\end{array}$ & $\begin{array}{c}\text { (d) } \\
\text { IR interactions }\end{array}$ \\
\hline d1 & $\begin{array}{l}-0.055 \\
(0.636) \\
\end{array}$ & $\begin{array}{l}-0.028 \\
(0.815) \\
\end{array}$ & - & $\begin{array}{l}-0.048 \\
(0.653) \\
\end{array}$ \\
\hline d2 & $\begin{array}{l}-0.070 \\
(0.555) \\
\end{array}$ & $\begin{array}{l}-0.020 \\
(0.883) \\
\end{array}$ & $\begin{array}{c}0.093 \\
(0.155) \\
\end{array}$ & $\begin{array}{l}-0.079 \\
(0.489) \\
\end{array}$ \\
\hline d3 & $\begin{array}{l}-0.064 \\
(0.604)\end{array}$ & $\begin{array}{l}-0.363 \\
(0.225)\end{array}$ & $\begin{array}{l}\mathbf{0 . 1 3 1 *} \\
(0.066)\end{array}$ & $\begin{array}{l}-0.083 \\
(0.577)\end{array}$ \\
\hline d4 & $\begin{array}{l}-0.026 \\
(0.850)\end{array}$ & - & $\begin{array}{l}\mathbf{0 . 1 8 2 *}^{*} \\
(0.069)\end{array}$ & - \\
\hline d1IR & - & - & - & $\begin{array}{c}\mathbf{0 . 1 1 0} \text { ***} \\
(0.000)\end{array}$ \\
\hline $\mathrm{d} 2 \mathrm{IR}$ & - & - & - & $\begin{array}{c}\mathbf{0 . 1 2 1 * * *} \\
(0.000)\end{array}$ \\
\hline d3IR & - & - & - & $\begin{array}{c}0.123^{* * *} \\
(0.000)\end{array}$ \\
\hline$d 4 I R$ & - & - & - & $\begin{array}{c}\mathbf{0 . 1 1 4}{ }^{\star * *} \\
(0.000)\end{array}$ \\
\hline logRtot & 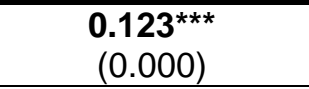 & $\begin{array}{c}0.109 * * * \\
(0.000)\end{array}$ & $\begin{array}{l}\mathbf{0 . 0 4 7 *} \\
(0.054)\end{array}$ & $\begin{array}{c}\mathbf{0 . 1 2 5 * * *} \\
(0.000)\end{array}$ \\
\hline $\log E m p$ & $\begin{array}{c}-0.244^{* * *} \\
(0.000)\end{array}$ & $\begin{array}{c}-0.247^{* * *} \\
(0.000)\end{array}$ & $\begin{array}{c}-0.124^{* * *} \\
(0.000)\end{array}$ & $\begin{array}{c}-0.240^{* * *} \\
(0.000)\end{array}$ \\
\hline $\log E m p^{\wedge} 2$ & 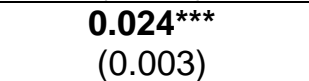 & $\begin{array}{c}0.022 \\
(0.272)\end{array}$ & $\begin{array}{l}\mathbf{0 . 0 2 2}^{\star *} \\
(0.021)\end{array}$ & 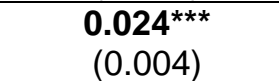 \\
\hline expint & $\begin{array}{c}\mathbf{0 . 1 7 6 * * *} \\
(0.010)\end{array}$ & $\begin{array}{c}0.052 \\
(0.654)\end{array}$ & $\begin{array}{c}\mathbf{0 . 2 4 2 * \star *} \\
(0.002)\end{array}$ & $\begin{array}{c}\mathbf{0 . 1 8 1 * \star *} \\
(0.000)\end{array}$ \\
\hline cobasic & $\begin{array}{l}-0.096 \\
(0.159) \\
\end{array}$ & $\begin{array}{l}-0.149 \\
(0.452) \\
\end{array}$ & $\begin{array}{c}-0.074 \\
(0.341) \\
\end{array}$ & $\begin{array}{c}-0.097 \\
(0.160) \\
\end{array}$ \\
\hline comkt & $\begin{array}{c}\mathbf{0 . 1 8 4 * * *} \\
(0.002)\end{array}$ & $\begin{array}{c}0.150 \\
(0.145)\end{array}$ & $\begin{array}{c}\mathbf{0 . 1 8 3 * * *} \\
(0.005)\end{array}$ & $\begin{array}{c}\mathbf{0 . 1 8 7 * * *} \\
(0.002)\end{array}$ \\
\hline pdt_quality & $\begin{array}{c}\mathbf{0 . 0 7 7 * * *} \\
(0.000)\end{array}$ & $\begin{array}{l}\mathbf{0 . 0 6 5}^{*} \\
(0.060) \\
\end{array}$ & $\begin{array}{l}\mathbf{0 . 0 9 8}^{\star \star * *} \\
(0.001)\end{array}$ & $\begin{array}{c}\mathbf{0 . 0 7 7 * * *} \\
(0.000)\end{array}$ \\
\hline pdt_out & $\begin{array}{l}-0.147^{*} \\
(0.058)\end{array}$ & $\begin{array}{l}-0.151 \\
(0.161)\end{array}$ & $\begin{array}{l}-0.222 \\
(0.104)\end{array}$ & $\begin{array}{c}-0.156^{* *} \\
(0.046)\end{array}$ \\
\hline mkt_novelty & $\begin{array}{c}\mathbf{0 . 1 7 4 * * *} \\
(0.000)\end{array}$ & $\begin{array}{c}0.053 \\
(0.492) \\
\end{array}$ & $\begin{array}{c}\mathbf{0 . 2 7 9 * * *} \\
(0.000)\end{array}$ & $\begin{array}{c}0.177^{* * *} \\
(0.000)\end{array}$ \\
\hline industry dummies & included & included & included & included \\
\hline constant & $\begin{array}{c}2.067^{\star \star * *} \\
(0.000) \\
\end{array}$ & $\begin{array}{c}\mathbf{2 . 3 1 6 * * *} \\
(0.000) \\
\end{array}$ & $\begin{array}{c}2.269 * * \star \\
(0.000) \\
\end{array}$ & $\begin{array}{c}2.065^{\star \star *} \\
(0.000) \\
\end{array}$ \\
\hline $\begin{array}{l}\text { obs } \\
\text { Log likelihood }\end{array}$ & $\begin{array}{c}2231 \\
-2695.672\end{array}$ & $\begin{array}{c}749 \\
-906.636\end{array}$ & $\begin{array}{c}1482 \\
-1787.78\end{array}$ & $\begin{array}{c}2231 \\
-2694.772\end{array}$ \\
\hline Wald test & $x^{2}(35)=342.47^{* \star *}$ & $\chi^{2}(34)=932.87^{* \star *}$ & $x^{2}(34)=237.03^{* \star *}$ & $\chi^{2}(38)=344.54^{\star \star *}$ \\
\hline $\begin{array}{l}\text { Wald test of independent } \\
\text { eqs. (no sample selection) }\end{array}$ & $\begin{array}{c}x^{2}(1)=0.24 \\
(0.627)\end{array}$ & $\begin{array}{c}x^{2}(1)=0.36 \\
(0.548)\end{array}$ & $\begin{array}{c}x^{2}(1)=0.28 \\
(0.596)\end{array}$ & $\begin{array}{c}x^{2}(1)=0.04 \\
(0.851)\end{array}$ \\
\hline
\end{tabular}

With this purpose in mind, the marginal effects defined by Equations 12 and 13 were computed for each number of innovative inputs at progressively higher levels of IR (identified, as in the indirect approach, by deciles) as well as in correspondence to its average value. The resulting estimates are reported in Table 11, together with the Wald one-sided tests under the null of nonpositive effects. Table 11 strongly supports the hypothesis of a specific catalysing role for IR, going 
much beyond a simple yes-or-no decision. Indeed, not only does the sign of the marginal effects switch from negative to positive as long as a minimum IR activity is performed, but all the effects become significant and monotonically increase over the rows in the table, once the $50^{\text {th }}$ percentile threshold level for IR has been reached (this threshold being the same as that singled out in the indirect analysis; see Table 7 for a direct comparison) ${ }^{35}$.

Table 11: Threshold (marginal) effect of internal research expenditure on the innovative returns associated with different numbers of innovative inputs.

\begin{tabular}{|c|c|c|c|c|}
\hline & d1 & d2 & d3 & d4 \\
\hline \multirow{2}{*}{$\mathrm{IR}=0$} & -0.048 & -0.079 & -0.083 & \multirow{2}{*}{0} \\
\hline & (0.673) & $(0.755)$ & $(0.711)$ & \\
\hline \multirow{2}{*}{$I R=\min (I R \mid I R>0)$} & 0.028 & 0.005 & 0.002 & $0.079 * \star \star$ \\
\hline & $(0.394)$ & $(0.482)$ & $(0.494)$ & $(0.000)$ \\
\hline \multirow{2}{*}{ IR = IR50 } & $0.275^{\star \star \star}$ & $0.278^{\star \star \star *}$ & $0.280 * \star *$ & $0.335^{\star \star \star}$ \\
\hline & (0.005) & $(0.005)$ & (0.009) & $(0.000)$ \\
\hline \multirow{2}{*}{ IR = IR60 } & $0.387^{* * *}$ & $0.402^{* * *}$ & $0.406^{* \star *}$ & $0.451^{\star \star \star}$ \\
\hline & $(0.000)$ & $(0.000)$ & $(0.000)$ & $(0.000)$ \\
\hline \multirow{2}{*}{ IR = IR70 } & $0.486 * * *$ & $0.511^{* * *}$ & $0.517^{* \star *}$ & $0.553^{* \star *}$ \\
\hline & (0.000) & $(0.000)$ & $(0.000)$ & (0.000) \\
\hline \multirow{2}{*}{ IR = IR80 } & $0.561^{* * *}$ & $0.593^{* * *}$ & $0.601^{* \star *}$ & $0.631^{\star \star *}$ \\
\hline & $(0.000)$ & (0.000) & (0.000) & (0.000) \\
\hline \multirow{2}{*}{ IR = IR90 } & $0.653^{* * *}$ & $0.695^{\star \star *}$ & $0.704^{\star \star *}$ & $0.726^{* \star *}$ \\
\hline & $(0.000)$ & $(0.000)$ & $(0.000)$ & $(0.000)$ \\
\hline \multirow{2}{*}{ Average } & $0.316^{\star \star \star}$ & $0.323^{\star \star \star}$ & $0.326^{\star * *}$ & $0.378^{\star \star \star}$ \\
\hline & (0.002) & (0.001) & $(0.000)$ & $(0.000)$ \\
\hline
\end{tabular}

${ }^{35}$ Such a result might raise the doubt that a simple scale effect is in action here: higher IR expenditures are likely to be realised by larger firms which could be, in turn, better able to manage multiple innovative strategies. However, it seems worthwhile to remember here that Table 11 is the result of a truncated regression model already checking for firms' size through both employees and their square, a control which should have cleared our results of any dimensional effect. However, in order for this doubt to be dispelled completely, the same exercise was replicated interacting a dimensional variable (either employees or turnover instead of IR) with the innovative input dummies: unlike the IR case, the corresponding marginal effects proved to be negative and not significant as long as higher threshold size levels were imposed. Moreover, the same test was performed substituting alternative innovative investments and total innovative expenditures for IR; once again, no significant results emerged, thus confirming that it is IR per se, and not a generic dimensional effect operating through any innovative input, that generates an advantage for the firm to combine more than one innovative activity (results from these robustness checks are available upon request). 
In addition, the marginal performance effects associated with the number of innovative inputs turned out to monotonically grow from left to right only once IR>IR50. Such a result indicates that a firm's advantage in simultaneously pursuing multiple innovative activities becomes evident only when a given threshold in internal $R \& D$ has been overcome. In other words, the catalysing effect of IR not only emerges with regard to complementarity (between two, three or four inputs, down the rows of Table 11), but also with regard to clustering (that is, switching to the simultaneous adoption of two, three or four innovative inputs, along the columns of Table 11$)^{36}$.

\subsection{A direct test for complementarity and substitutability}

Previous analyses have suggested that innovative performance depends on the pursued innovative strategies in a rather complex way. We can be more precise and put forward an assessment of the innovation function over the entire set $S$ of $2^{4}=16$ alternative combinations of the available (dichotomous ${ }^{37}$ ) innovative inputs, thus accounting for the peculiar nature and role each of them has within the innovative process. In this context, eq. (10) becomes:

$Y(S, Z)=f\left(S_{0000}, S_{1000}, \ldots, S_{1111}, Z\right)$

where $\mathrm{Y}$ is the innovation intensity (logTurninn) and $\mathrm{Z}$ has the usual meaning. The set of choice variables in $S$ (IRd, ERd, MACd and TAd) will then be complementary if and only if the innovation function $Y$ turns out to be supermodular with respect to the lattice $S$ (see Section 2.2):

$Y\left(S^{\prime} \vee S^{\prime \prime}, Z\right)+Y\left(S^{\prime} \wedge S^{\prime \prime}, Z\right) \geq Y\left(S^{\prime}, Z\right)+Y\left(S^{\prime \prime}, Z\right)$

However, the empirical check of such a condition looks (and indeed is) very burdensome in spite of the useful simplifications the theory of supermodularity suggests (see Section 2.3.1). First of all, as Topkis (1998) demonstrated, a necessary and sufficient condition in order for a function to be supermodular in (all) its arguments is that such arguments are all pairwise complementary (for

${ }^{36}$ It seems important in this regard to observe how the first column of Table 11 allows us to exclude a standard decreasing-returns explanation of clustering, that is the idea that the marginal returns associated with the analysed input decrease with its expenditure level, making it more advantageous for the firm to perform alternative activities instead of increasing the investment in the same input. If such were the case, we should expect to observe the marginal returns associated with IR to decrease monotonically as long as its expenditure levels go up, which is not at all the case here; indeed, coefficients in column d1 monotonically increase rather than decrease).

${ }^{37}$ As discussed in Section 2.3.1, multicollinearity problems prevent us from using the continuous measures of the innovative inputs. As a consequence - differently from the previous section - the direct test cannot be run over increasing IR deciles. 
all the possible values of the other practices). It follows that $\left(\begin{array}{l}n \\ 2\end{array}\right) 2^{n-2}$ non-trivial inequality constraints would have to be jointly tested in order for condition (15) to be proved ${ }^{38}$. A second simplification directly follows: given that it suffices to check pairwise complementarity over any subset of arguments in order for the function $Y$ to be supermodular in that subset, we can restrict our attention to bi-dimensional subsets only, thus ending up with testing each pair of inputs separately (that is, performing a $2^{\mathrm{n}-2}$ joint one-sided test for each couple).

Thus, considering for example the first two innovative inputs (IR and ER), the complementary condition expressed by (15) will simplify to:

$Y\left(S_{11 k l}, Z\right)+Y\left(S_{00 k l}, Z\right) \geq Y\left(S_{10 k l}, Z\right)+Y\left(S_{01 k l}, Z\right)$

(16) tests for the existence of an absolute advantage for the firm in simultaneously performing internal and external research whatever the other investment decisions are, $((k, l)=\{(0,0) ;(1,0)$; $(0,1) ;(1,1)\}$ representing the possible combinations of a firm's "residual” investment strategies; in this example MACd and TAd).

Such a procedure, besides simplifying an otherwise overwhelming test, allows us to avoid the possible controversial effects which may arise from a general, overall supermodularity test ${ }^{39}$. This seems to be particularly important in our context, since the previous analyses suggest the possible coexistence within the innovative process of complementarity and substitutability relationships we need to distinguish between. The adopted methodology fulfils this need by separately investigating the nature of the interactions taking place between each pair of inputs, given (which is not the same as neglecting) the remaining investment decisions and the impact they produce on innovation intensity.

In order to perform such investigation empirically, consistent estimates of the effect each strategy produces on firm's innovative intensity are needed: the first step will then consist in regressing logTurninn on a set of state dummies $S_{\mathrm{ijkl}}$ uniquely identifying the 16 input combinations (while checking, as usual, for firm's characteristics and industry fixed effects).

$38\left(\begin{array}{l}n \\ 2\end{array}\right)$ representing the total number of pairwise combinations we can get out of $n$ inputs while $(n-2)$ is the number of residual investment decisions we should check for, each of them taking on two possible values $(0$, 1 ), for a total of $2^{n-2}$ different cases to be tested. In our case, given that $n=4$, the problem will then consist in the simultaneous (not so easy-to-handle) test of 24 inequality constraints.

${ }^{39}$ Which might lead us, for example, to reject the complementarity hypothesis whenever even a single couple of inputs turns out to be substitute, without giving us any other information about the reason behind the test failure. 
The set of inequality constraints identified by eq. (15) will be then re-written in terms of the coefficients $\beta_{\mathrm{ijkl}}$ associated with the above-defined state variables $\mathrm{S}_{\mathrm{ijkl}}$; so for example condition (16), identifying the four inequalities to be simultaneously verified in order for the first and the second input (IR and ER) to be strictly complementary, will be tested in the form:

$$
\left\{\begin{array}{l}
\left(\beta_{1100}+\beta_{0000}\right)-\left(\beta_{1000}+\beta_{0100}\right) \geq 0 \\
\left(\beta_{1110}+\beta_{0010}\right)-\left(\beta_{1010}+\beta_{0110}\right) \geq 0 \\
\left(\beta_{1101}+\beta_{0001}\right)-\left(\beta_{1001}+\beta_{0101}\right) \geq 0 \\
\left(\beta_{1111}+\beta_{0011}\right)-\left(\beta_{1011}+\beta_{0111}\right) \geq 0
\end{array}\right.
$$

with at least one of the four constraints holding strictly.

Analogous four-inequalities systems were defined for each pairwise combination of the four innovative inputs we focus on; for each of them, the null hypothesis that the four constraints are jointly met were tested against the alternative of unconstrained coefficients. In matrix form:

$$
\left\{\begin{array}{l}
H_{0}: R_{i j} \beta \geq 0 \\
H_{1}: R_{i j} \beta \gtrsim 0
\end{array}\right.
$$

where $R_{i j}(i \neq j, i, j=1, . ., 4)$ is a ( $\left.4 \times 16\right)$ constraint matrix identifying, for each pair of inputs, the four inequality constraints to be analysed in order for the complementarity hypothesis to be tested, $\beta$ representing the $(16 \times 1)$ vector of state-variables coefficients.

The test accepts the null of strict complementarity when the four constraints are jointly met (with at least one of them holding strictly) and rejects it when such restrictions are not simultaneously satisfied (that is, when at least one of them, no matter which, turns out to be lower than zero) $)^{40}$.

A test for strict substitutability can be symmetrically designed by just changing the sign of the inequalities:

${ }^{40}$ As has been argued by Kodde and Palm (1986), the alternative hypothesis accounts here just for the case of completely unrestricted parameters: this means that a rejection of the null cannot be taken as evidence in favour of substitutability, simply implying the absence of complementarity among the four considered innovative inputs. As discussed in Section 2.3.1, the framework developed by Kodde and Palm for inequality constraints does not allow for direct testing of the complementarity hypothesis against the substitutability one. 


$$
\left\{\begin{array}{l}
H_{0}: R_{i j} \beta \leq 0 \\
H_{1}: R_{i j} \beta \Varangle 0
\end{array}\right.
$$

A large sample Wald test has then to be implemented in order for the two hypotheses complementarity and substitutability - to be (separately) tested against the unrestricted alternative. The procedure we used follows Kodde and Palm (1986) in computing the Wald (or distance) statistics as:

$\mathrm{D}=\mathrm{D}_{0}-\mathrm{D}_{1}$

$D_{0}\left(D_{1}\right)$ being the minimum distance from the unrestricted estimate $\bar{\beta}$ to the closest feasible estimate under $\mathrm{H}_{0}\left(\mathrm{H}_{1}\right)$. Bearing in mind that for both the complementarity and the substitutability test, the alternative hypothesis has been defined in such a way that it coincides with the unrestricted estimate $\bar{\beta}$, the Wald statistics reduces, in both cases, to $\mathrm{D}=\mathrm{D}_{0}$.

It remains then to compute $\mathrm{D}_{0}$ : let $\mathrm{S}_{0}$ denote the feasible space for $\mathrm{R} \beta$ under the null ${ }^{41}$ and $R \hat{\beta}_{0}$ be the orthogonal projection of $R \bar{\beta}$ onto $\mathrm{S}_{0}$, that is:

$$
R \hat{\beta}_{0} \ni^{\prime} \min _{R \beta \in S_{0}}(R \bar{\beta}-R \beta)^{\prime} \Sigma^{-1}(R \bar{\beta}-R \beta)=\min _{R \beta \in S_{0}}\|R \bar{\beta}-R \beta\|=D_{0}
$$

where $\|R \bar{\beta}-R \beta\|$ represents the distance function - in the metric of $\Sigma$ - of the vector $\mathrm{R} \beta$ from $R \bar{\beta}$. Since $\mathrm{S}_{0}$ is convex, $R \hat{\beta}_{0}$ will be uniquely determined and so will the Wald statistic $\mathrm{D}$, equal to:

$$
D=D_{0}=\left(R \bar{\beta}-R \hat{\beta}_{0}\right)^{\prime} \Sigma^{-1}\left(R \bar{\beta}-R \hat{\beta}_{0}\right)=\left\|R \bar{\beta}-R \hat{\beta}_{0}\right\|
$$

This test differs from the traditional Wald test since the large sample distribution of its statistic under the null hypothesis is no more a standard $\chi^{2}$ with a number of degrees of freedom equal to the number of restrictions we are testing for. Once a system of inequality restrictions has been imposed, it turns out to be a combination of $\chi^{2}$ distributions whose weights $\mathrm{w}_{\text {ip }}$ (summing up to one, as proved by Shapiro, 1985) denote the normal orthant probability associated with i of the $\mathrm{p}$ elements of $R \hat{\beta}_{0}$ (that is, the probability that $\mathrm{i}$ of these p elements are strictly positive).

\footnotetext{
${ }^{41} S_{0}=(0,+\infty)$ when strict complementarity is tested, $(-\infty, 0)$ when strict substitutability is looked for.
} 
Kodde and Palm (1986) computed lower and upper bounds for this kind of test. Given a chosen significance level, we can reject the null whenever the distance statistic D exceeds the corresponding upper bound value; we cannot reject it when $\mathrm{D}$ is smaller than the lower bound critical value. The test is inconclusive if $\mathrm{D}$ lies between the two bounds.

Following the methodological guidelines given above, the share of innovative turnover was regressed over the set $S$ of exclusive innovative strategies and the standard set of controls. The unconstrained coefficient estimates were then used in order for the Wald statistic (22) to be computed on each pairwise combination of innovative inputs.

The nature of the adopted dependent variable, only accounting for the intensity of product innovation, made it necessary (as was the case in Section 5.2), to drop firms realising process innovations only. Such a selection (which did not appear to generate any significant sample bias when a generic clustering effect was looked for, see Table 10) turned out to be significant in this case $^{42}$, thus calling for a Heckman correction procedure (Heckman, 1976) in order to achieve consistent parameter estimates. The Heckman-corrected estimates are presented in Table 12.

As far as firm's characteristics are concerned, no relevant differences emerge with respect to the truncated model estimates we reported in Table 10, thus confirming the stability of our results across different model specifications and innovative strategy definitions. However, the role of total innovative expenditure, still significant, turns out to be strongly reduced in magnitude once all the possible combinations of innovative inputs, instead of just the number of innovative inputs firms have invested in, are checked for. However, these estimates should be considered here mainly as a basis for computing the Wald (distance) statistics, whose values are reported in Table 13.

The most interesting result emerging from Table 13 is the sharp contrast between the subgroup of pairwise combinations directly involving IR (which are represented by the first three rows in the table) and the residual group made up of non-IR-involving strategies (shaded rows). The complementarity hypothesis turns out to be accepted whenever internal $R \& D$ activities are performed, a result which is strengthened by the opposite hypothesis (substitutability) being significantly rejected in two out of three cases (being inconclusive in the residual one). This means that interacting IR with any other innovative input generates systemic effects making "the whole larger than the sum of its parts”.

42 The significance of such a sample selection bias is confirmed by both the Wald test of independent equations (rejecting the null of no sample selection at a 1\% level of significance) and in the two-step estimates the coefficient associated with the inverse Mills ratio (significant at 10\%). 
Table 12: Heckman-corrected estimates of logTurninn on the alternative innovative strategies

\begin{tabular}{|c|c|}
\hline $\mathrm{S}_{0000}$ & $\begin{array}{c}2.498^{* * *} \\
(0.000) \\
\end{array}$ \\
\hline $\mathrm{S}_{1000}$ & $\begin{array}{c}2.518^{* * *} \\
(0.000)\end{array}$ \\
\hline $\mathrm{S}_{0100}$ & $\begin{array}{c}2.559 * * * \\
(0.000) \\
\end{array}$ \\
\hline $\mathrm{S}_{0010}$ & $\begin{array}{c}2.772^{* * *} \\
(0.000) \\
\end{array}$ \\
\hline $\mathrm{S}_{0001}$ & $\begin{array}{c}2.706^{* \star *} \\
(0.000) \\
\end{array}$ \\
\hline $\mathrm{S}_{1100}$ & $\begin{array}{c}2.554^{* * *} \\
(0.000) \\
\end{array}$ \\
\hline $\mathrm{S}_{1010}$ & $\begin{array}{c}2.612^{* * *} \\
(0.000)\end{array}$ \\
\hline $\mathrm{S}_{1001}$ & $\begin{array}{c}2.645^{\star * *} \\
(0.000) \\
\end{array}$ \\
\hline $\mathrm{S}_{0110}$ & $\begin{array}{c}2.560 * * \star \\
(0.000)\end{array}$ \\
\hline $\mathrm{S}_{0101}$ & $\begin{array}{l}2.831^{\star * *} \\
(0.000)\end{array}$ \\
\hline $\mathrm{S}_{0011}$ & $\begin{array}{l}2.758 * * * \\
(0.000)\end{array}$ \\
\hline $\mathrm{S}_{1110}$ & $\begin{array}{c}2.635^{\star \star *} \\
(0.000)\end{array}$ \\
\hline $\mathrm{S}_{1101}$ & $\begin{array}{c}2.535^{* * *} \\
(0.000) \\
\end{array}$ \\
\hline $\mathrm{S}_{1011}$ & $\begin{array}{l}2.664^{* * *} \\
(0.000)\end{array}$ \\
\hline $\mathrm{S}_{0111}$ & $\begin{array}{l}2.225^{* * *} \\
(0.000) \\
\end{array}$ \\
\hline $\mathrm{S}_{1111}$ & $\begin{array}{c}2.643^{* * *} \\
(0.000)\end{array}$ \\
\hline logRtot & $\begin{array}{c}\mathbf{0 . 0 3 0 * * *} \\
(0.000)\end{array}$ \\
\hline $\log E m p$ & $\begin{array}{c}-0.150 * * \star \\
(0.000)\end{array}$ \\
\hline $\operatorname{logEmp\wedge 2}$ & $\begin{array}{c}0.023^{\star * *} \\
(0.006) \\
\end{array}$ \\
\hline expint & $\begin{array}{l}0.205^{* * *} \\
(0.003)\end{array}$ \\
\hline comkt & $\begin{array}{l}0.137^{* *} \\
(0.015)\end{array}$ \\
\hline pdt_quality & $\begin{array}{l}\mathbf{0 . 0 8 1 * * *} \\
(0.000)\end{array}$ \\
\hline pdt_out & $\begin{array}{c}-0.170 * * \\
(0.031)\end{array}$ \\
\hline mkt_novelty & $\begin{array}{l}0.180 * * * \\
(0.000)\end{array}$ \\
\hline industry dummies & included \\
\hline lambda (inverse Mills ratio) & $\begin{array}{l}-0.208^{*} \\
(0.097) \\
\end{array}$ \\
\hline Observations & 3045 (814 censored) \\
\hline Wald $x^{2}$ & $\begin{array}{c}14145.09 * \star \star \\
(0.000)\end{array}$ \\
\hline $\begin{array}{l}\text { Wald test of independent } \\
\text { equations (no sample selection) }\end{array}$ & $\begin{array}{c}x^{2}(1)=37.51^{* * *} \\
(0.000)\end{array}$ \\
\hline P-values in brackets;* sign. at 10 & n. at $5 \% ;{ }^{\star \star \star}$ sign. at $1 \%$ \\
\hline
\end{tabular}


Table13: Wald complementarity and substitutability statistics.

\begin{tabular}{|c|c|c|}
\hline \multirow[b]{2}{*}{$\mathbf{H}_{\mathbf{0}}$} & \multicolumn{2}{|c|}{ Innovation intensity = logTurninn } \\
\hline & complementarity & substitutability \\
\hline IR-ER & $\underline{0.189}$ & $9.186 *$ \\
\hline IR-MAC & $\underline{1.610}$ & $7.142 *$ \\
\hline IR-TA & $\underline{0.394}$ & 3.651 \\
\hline ER-MAC & $7.409 *$ & $\underline{0.105}$ \\
\hline ER-TA & 5.600 & $\underline{0.014}$ \\
\hline MAC-TA & 2.480 & $\underline{0.011}$ \\
\hline
\end{tabular}

A symmetric result emerges from the three last rows, testing super- and sub-modularity over pairwise combinations of inputs not involving IR. While the complementarity hypothesis turns out to be significantly rejected here in one out of three cases (that is, the interaction between external R\&D and embodied technological acquisitions) and inconclusive in the other two, the substitutability hypothesis is always accepted at a $10 \%$ significance level.

Once again, it is in-house $R \& D$ which plays what we defined as a "catalysing” role, raising the innovative impact of the (otherwise substitutable) innovative inputs it interacts with.

\section{Conclusions}

This paper has explored the way different innovative inputs interact with each other within the innovative process using firm-level data from the third Italian CIS. The basic research question was to investigate whether the nature of such interactions has to be considered in absolute terms (either of complementarity or substitutability) or, instead, as a relative property of the innovation activity, holding only over some innovative input combinations or just emerging over limited subsets of input expenditure levels (threshold effects).

With this purpose in mind, the interactions between four different sources of innovation internal and external R\&D, embodied and disembodied technological acquisitions - were simultaneously explored through two testing frameworks for complementarity: direct and indirect. 
Results from both the approaches show that the innovative process is a highly diversified phenomenon combining within itself both complementarity and substitutability relationships, depending both on the typology of the targeted innovation output and on the particular combination of innovative inputs we focus on. In particular, it is in-house $R \& D$ that seems to create the precondition allowing firms to enjoy complementarity effects. Indeed, both correlation and performance analyses show that the possibility of exploiting complementarity effects from simultaneous investment in more than one innovative input is subordinated to having undertaken a minimum amount of internal research. In this context, we can think of internal $R \& D$ as being the catalyst that accelerates the "reactions" taking place within the innovative process, either by improving the individual qualities of the inputs it interacts with or creating that absorptive capacity which allows for systemic effects to be established and exploited.

The implication of this result is that a role for in-house $R \& D$ emerges, beyond its direct effect in generating an innovative output. Even if internal research is not a necessary condition for a firm to be innovative, it should still be carried out and encouraged because of its important role in the generation of synergies that amplify the impacts of the other innovative inputs it interacts with.

\section{References}

Arora A. (1996): Testing for Complementarities in Reduced-Form Regressions: A Note. Economics Letters, 50, 51-55.

Arora A., Gambardella A. (1990): Complementarity and External Linkages: The Strategies of the Large Firms in Biotechnology. Journal of Industrial Economics, 38, 362-79.

Athey S., Stern S. (1998): An Empirical Framework for Testing Theories About Complementarity in Organizational Design. NBER Working Paper n. 6600, Cambridge (Mass.).

Athey S., Stern S. (2002): The Impact of Information Technology on Emergency Health Care Outcomes. RAND Journal of Economics, 33, 399-432.

Basant R., Fikkert B. (1996): The Effects of R\&D, Foreign Technology Purchase, Domestic and International Spillovers on Productivity in Indian Firms. Review of Economics and Statistics, 78, 187-99.

Belderbos R., Lokshin B., Carree M. (2006): Complementarity in R\&D Cooperation Strategies. Review of Industrial Organization, 28, 401-26.

Beneito P. (2003): Choosing among Alternative Technological Strategies: an Empirical Analysis of Formal Sources of Innovation. Research Policy, 32, 693-713.

Bresnahan T., Brynjolfsson E., Hit L. M. (2002): Information Technology, Workplace Organization, and the Demand for Skilled Labor: Firm-Level Evidence. Quarterly Journal of Economics, 117, 339-75.

Cameron, A.C., Trivedi, P.K. (2005): Microeconometrics, Methods and Applications. Cambridge University Press, Cambridge. 
Cassiman B., Veugelers R. (2002): Complementarity in the Innovation Strategy: Internal R\&D, External Technology Acquisition and Cooperation. CEPR Discussion Paper n. 3284, CEPR, London.

Cassiman B., Veugelers R. (2006): In search of Complementarity in the Innovation Strategy: Internal R\&D and External Knowledge Acquisition. Management Science, 52, 68-82.

Cleveland, W.S. (1979) Robust Locally Weighted Regression and Smoothing Scatterplots, Journal of the American Statistical Association, 74, 829-836.

Cohen W. M., Levinthal D.A. (1989): Innovation and Learning: Two faces of R\&D., Economic Journal, 99, 569-596.

Conte A., Vivarelli M. (2005): One or Many Knowledge Production Functions? Mapping Innovative Activity Using Microdata. IZA Discussion Paper n. 1878, IZA, Bonn.

Crèpon B., Duguet E., Mairesse J. (1998): Research, Innovation and Productivity: an Econometric Analysis at the Firm Level. Economics of Innovation and New technology, 7, 115-156.

Fernandez-Bagües M. (2004): Complementarity in Innovation Strategies: Evidence from Pharmaceutical Dynamic Panel Data. Paper presented at the $30^{\text {th }}$ EARIE Conference in Helsinki.

Greene, W.H. (2003): Econometric Analysis. Fifth edition. Prentice Hall, Upper Saddle River, NJ.

Griffith R., Redding S., Van Reenen J. (2003): R\&D and Absorptive Capacity: Theory and Empirical Evidence. Scandinavian Journal of Economics, 105, 99-118.

Griliches Z. (1979): Issues in Assessing the Contribution of R\&D to Productivity Growth. Bell Journal of Economics, 10, 92-116.

Griliches Z. (1998): R\&D and Productivity. Chicago University Press, Chicago.

Heckman, J.J. (1976): The Common Structure of Statistical Models of Truncation, Sample Selection and Limited Dependent Variables and a Simple Estimator for Such Models. Annals of Economic and Social Measurement, 5, 475-492.

Hobijn B. (1999): Identifying Sources of Growth. Mimeo, New York University, New York.

ISTAT (2004): Statistiche sull' Innovazione delle Imprese, Settore Industria, Anni 1998-2000. ISTAT, Roma.

Kodde D. A., Palm F. C. (1986): Wald Criteria for Jointly Testing Equality and Inequality Restrictions. Econometrica, 54, 1243-48.

Kudô A. (1963): A Multivariate Analogue of the One-sided Test. Biometrika, 50, 403-18.

Lokshin B., Belderbos R., Carree M. (2006): Internal and External R\&D: Complements or Substitutes? Evidence from a Dynamic Panel Data Model. Hi-Stat Discussion Paper Series d06-163. Institute of Economic Research, Hitotsubashi University, Tokyo.

Lokshin B., Carree M., Belderbos R. (2004): Testing for Complementarity and Substitutability in Case of Multiple Practices. METEOR memorandum RM04002, University of Maastricht, Maastricht.

Lööf H., Heshmati A. (2003): On the Relationship Between Innovation and Performance: A Sensitivity Analysis. Economics of Innovation and New Technology, 15, 317-344.

Mairesse J., Mohnen P. (2002): Accounting for Innovation and Measuring Innovativeness: An Illustrative Framework and an Application. American Economic Review, Papers and Proceedings, 92, 226-30. 
Mairesse, J., Mohnen, P. (2004): The importance of R\&D for Innovation: A Reassessment Using French Survey Data. MERIT-Infonomics Research Memorandum series 2004-022, MERIT, Maastricht.

Milgrom P., Roberts J. (1995): Complementarities and Fit: Strategy, Structure and Organizational Change in Manufacturing. Journal of Accounting and Economics, 19, 179-208.

Mohnen P., Röller L. H. (2005): Complementarities in Innovation Policy. European Economic Review, 49, 1431-50.

Pakes A., Griliches Z. (1984): Patents and the R\&D at Firm Level: A First Look. In Griliches, Z. (ed.): $R \& D$, Patents and Productivity. University of Chicago Press, Chicago, 390-409.

Parisi M.L., Schiantarelli F., Sembenelli A. (2006): Productivity, Innovation and R\&D: Micro Evidence for Italy. European Economic Review, 50, 2037-2061.

Pavitt K. (1984): Sectoral Patterns of Technical Change: Towards a Taxonomy and a Theory. Research Policy, 13, 343-373.

Piva, M. - Vivarelli, M. (2006), Is Demand-Pulled Innovation Equally Important in Different Groups of Firms?, IZA Discussion Paper n. 1982, IZA, Bonn.

Piva, M. - Vivarelli, M. (2007), Corporate Skills as an Ex-Ante Incentive to R\&D Investment, IZA Discussion Paper n. 2562, IZA, Bonn.

Piga, C., Vivarelli, M. (2003), Sample Selection in Estimating the Determinants of Cooperative R\&D, Applied Economics Letters, 10, 243-46.

Piga C., Vivarelli M. (2004): Internal and External R\&D: A Sample Selection Approach. Oxford Bulletin of Economics and Statistics, 66, 457-82.

Pisano G. P. (1990): The R\&D Boundaries of the Firm: An Empirical Analysis. Administrative Science Quarterly, 35, 153-76.

Powell J. L. (1984): Least Squares Absolute Deviations Estimation for the Censored Regression Model. Journal of Econometrics, 25, 303-325.

Rosenberg N. (1976), Perspectives on Technology, Cambridge University Press, Cambridge.

Ruud P. A. (1984): Tests of Specification in Econometrics. Econometric Reviews, 3, 211-242.

Salter W. E. G. (1960), Productivity and Technical Change, Cambridge University Press, Cambridge.

Shapiro A. (1985): Asymptotic Distribution of Test Statistics in the Analysis of Moment Structures Under Inequality Constraints. Biometrika, 72, 133-144.

Solow R. (1960): Investment and Technological Progress. In Arrow, K., Karlin, S., Suppes, P. (eds.): Mathematical Methods in the Social Sciences, Stanford University Press, Stanford, 89-104.

Tobin J. (1958): Estimation of relationships for limited dependent variables. Econometrica, 26, 24-36.

Topkis D. M. (1998): Supermodularity and Complementarity. Princeton University Press, Princeton.

Veugelers R. (1997): Internal R\&D Expenditures and External Technological Sourcing. Research Policy, 26, 303-16.

Wolak F. (1989): Testing Inequality Constraints in Linear Econometric Models. Journal of Econometrics, 41, 205-35. 


\section{APPENDIX}

Table A1: Conditional correlation coefficients by MAC deciles.

\begin{tabular}{|c|c|c|c|c|c|c|}
\hline & $\begin{array}{l}\text { Correlation } \\
\text { (logIR-logER) }\end{array}$ & $\begin{array}{l}\text { Correlation } \\
\text { (logIR-logMAC) }\end{array}$ & $\begin{array}{c}\text { Correlation } \\
(\log I R-\log T A)\end{array}$ & $\begin{array}{l}\text { Correlation } \\
\text { (logER-logMAC) }\end{array}$ & $\begin{array}{l}\text { Correlation } \\
\text { (logER- ogTA) }\end{array}$ & $\begin{array}{c}\text { Correlation } \\
\text { (logMAC-logTA) }\end{array}$ \\
\hline $\begin{array}{l}\text { Full sample } \\
\text { (2966 obs) }\end{array}$ & 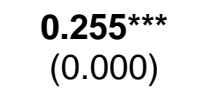 & $\begin{array}{c}-\mathbf{0 . 1 8 5}^{\star \star * *} \\
(0.000)\end{array}$ & $\begin{array}{c}\mathbf{0 . 0 5 5} \text { *** } \\
(0.000)\end{array}$ & $\begin{array}{c}-\mathbf{0 . 1 0 2}^{\star * *} \\
(0.000)\end{array}$ & $\begin{array}{c}\mathbf{0 . 1 9 3 * * *} \\
(0.000)\end{array}$ & $\begin{array}{c}0.009 \\
(0.457)\end{array}$ \\
\hline $\begin{array}{c}\text { MAC }>\mathbf{0} \\
\text { (2360 obs) }\end{array}$ & 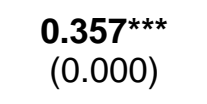 & $\begin{array}{c}-0.098^{* * *} \\
(0.000)\end{array}$ & $\begin{array}{c}\mathbf{0 . 1 4 8 * * *} \\
(0.000)\end{array}$ & $\begin{array}{c}-\mathbf{0 . 0 6 8 * * *} \\
(0.000)\end{array}$ & 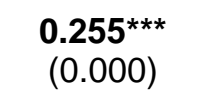 & $\begin{array}{c}0.001 \\
(0.936)\end{array}$ \\
\hline $\begin{array}{c}\text { MAC }>\text { MAC30 } \\
(2046 \text { obs })\end{array}$ & $\begin{array}{c}\mathbf{0 . 3 5 3 * * *} \\
(0.000)\end{array}$ & $\begin{array}{c}-0.092^{\star * *} \\
(0.000)\end{array}$ & $\begin{array}{l}\mathbf{0 . 1 5 2 * * *} \\
(0.000)\end{array}$ & $\begin{array}{c}-0.068^{* * *} \\
(0.000)\end{array}$ & $\begin{array}{l}\mathbf{0 . 2 6 2 * * *} \\
(0.000)\end{array}$ & $\begin{array}{c}0.018 \\
(0.224)\end{array}$ \\
\hline $\begin{array}{c}\text { MAC }>\text { MAC40 } \\
\quad(1778 \text { obs })\end{array}$ & $\begin{array}{c}\mathbf{0 . 3 4 9 * * *} \\
(0.000)\end{array}$ & $\begin{array}{c}-0.068^{\star * *} \\
(0.000)\end{array}$ & $\begin{array}{c}\mathbf{0 . 1 5 4} \text { *** } \\
(0.000)\end{array}$ & $\begin{array}{c}-0.040 * * \\
(0.012)\end{array}$ & $\begin{array}{c}\mathbf{0 . 2 7 9 * * *} \\
(0.000)\end{array}$ & 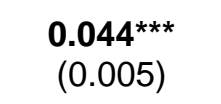 \\
\hline $\begin{array}{c}\text { MAC }>\text { MAC50 } \\
\quad(1478 \text { obs })\end{array}$ & $\begin{array}{c}\mathbf{0 . 3 2 3 * * *} \\
(0.000)\end{array}$ & $\begin{array}{c}-0.039 * * \\
(0.024)\end{array}$ & $\begin{array}{c}\mathbf{0 . 1 6 2 * * *} \\
(0.000)\end{array}$ & $\begin{array}{l}-0.009 \\
(0.615)\end{array}$ & $\begin{array}{c}\mathbf{0 . 2 9 7 * * *} \\
(0.000)\end{array}$ & $\begin{array}{c}\mathbf{0 . 0 7 6 * * *} \\
(0.000)\end{array}$ \\
\hline $\begin{array}{c}\text { MAC }>\text { MAC60 } \\
\quad(1184 \text { obs })\end{array}$ & $\begin{array}{c}\mathbf{0 . 3 1 0 * * *} \\
(0.000)\end{array}$ & $\begin{array}{c}-0.042^{* *} \\
(0.031)\end{array}$ & $\begin{array}{c}\mathbf{0 . 1 5 6 * * *} \\
(0.000)\end{array}$ & $\begin{array}{c}0.000 \\
(0.981)\end{array}$ & $\begin{array}{c}\mathbf{0 . 3 3 8 * * *} \\
(0.000)\end{array}$ & $\begin{array}{c}\mathbf{0 . 0 7 2 * * *} \\
(0.000)\end{array}$ \\
\hline $\begin{array}{c}\text { MAC }>\text { MAC70 } \\
\text { (889 obs) }\end{array}$ & $\begin{array}{c}\text { 0.328*** } \\
(0.000)\end{array}$ & $\begin{array}{l}-0.193 \\
0.390\end{array}$ & $\begin{array}{c}\mathbf{0 . 1 5 3 * * *} \\
(0.000)\end{array}$ & $\begin{array}{c}0.011 \\
(0.622)\end{array}$ & $\begin{array}{c}\mathbf{0 . 3 4 9 * * *} \\
(0.000)\end{array}$ & $\begin{array}{c}\mathbf{0 . 0 7 9 * * *} \\
(0.000)\end{array}$ \\
\hline $\begin{array}{c}\text { MAC }>\text { MAC80 } \\
\text { (593 obs) }\end{array}$ & $\begin{array}{c}\mathbf{0 . 2 8 4} * * * \\
(0.000)\end{array}$ & $\begin{array}{l}-0.038 \\
(0.172)\end{array}$ & $\begin{array}{c}\mathbf{0 . 1 1 9 * * *} \\
(0.000)\end{array}$ & $\begin{array}{l}\mathbf{0 . 0 4 6 *} \\
(0.093)\end{array}$ & $\begin{array}{c}\mathbf{0 . 3 5 1 * * *} \\
(0.000)\end{array}$ & $\begin{array}{c}\mathbf{0 . 1 0 0 * * *} \\
(0.000)\end{array}$ \\
\hline $\begin{array}{c}\text { MAC }>\text { MAC90 } \\
(294 \text { obs })\end{array}$ & 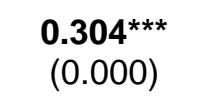 & $\begin{array}{l}-0.025 \\
(0.515)\end{array}$ & $\begin{array}{c}\mathbf{0 . 1 1 4 ^ { \star * * }} \\
(0.003)\end{array}$ & $\begin{array}{l}0.026 \\
0.506\end{array}$ & $\begin{array}{c}0.294^{\star * *} \\
(0.000)\end{array}$ & $\begin{array}{c}\mathbf{0 . 1 7 4 * * *} \\
(0.000)\end{array}$ \\
\hline
\end{tabular}

